\title{
Assessing the degree of international consumption risk sharing *
}

\author{
Constantino Hevia \\ Universidad Torcuato Di Tella
}

\author{
Luis Servén \\ World Bank
}

March 16, 2018

\begin{abstract}
This paper examines the extent of risk sharing for a group of 50 industrial and developing countries. The analysis is based on a model of partial consumption insurance whose parameters have the natural interpretation of coefficients of partial risk sharing even when the null hypothesis of perfect risk sharing is rejected. Results show that rich countries exhibit higher degrees of risk sharing than developing countries, and that the gap has widened over time. Other things equal, the degree of risk sharing is higher in smaller, more financially-open economies and in those possessing flexible exchange rate regimes.
\end{abstract}

Keywords: Incomplete risk sharing, Financial globalization.

JEL classification: E21; F36; F41

\footnotetext{
*Corresponding author: Constantino Hevia, Universidad Torcuato Di Tella, Av. Pres. Figueroa Alcorta 7350, C1428BCW Buenos Aires, Argentina. E-mail: chevia@utdt.edu. We thank Aart Kraay, Alex Werner, and seminar participants at IMF and UAM for useful discussions, and Vivian Norambuena for excellent research assistance. This work was supported by the World Bank's Knowledge for Change and Strategic Research programs. The views expressed here are only ours and do not necessarily reflect those of the World Bank, its Executive Directors, or the countries they represent.
} 


\section{Introduction}

A considerable analytical and empirical literature has been concerned with the extent of consumption risk sharing across countries. The relatively high sensitivity of aggregate consumption to domestic income shocks - equivalently, the low degree of comovement of aggregate consumption across countries - is one of the major puzzles in international macroeconomics (Obstfeld and Rogoff, 2001). In recent years, it has attracted renewed interest due to the growing degree of financial integration of economies across the world. The argument is straightforward: if financial markets are complete - in the sense that available assets span all idiosyncratic risks - the ratio of the marginal utilities of consumption of any pair of agents (or countries, in this paper's representative-agent framework) must be constant across dates and states of nature. That is, the economy features perfect consumption risk sharing. ${ }^{1}$ In turn, if risk sharing is imperfect and markets are incomplete, financial innovation that expands the set of tradeable assets (or reduces the costs of trading existing assets) should allow enhanced risk diversification, although it might also raise the overall exposure to risk. ${ }^{2}$ To the extent that the global increase in cross-border asset holdings over the last quarter century (Lane and Milesi-Ferretti, 2007) reflects such kind of innovation, it should be associated with a rise in risk sharing across countries.

A number of papers have performed empirical tests of the null hypothesis of perfect consumption risk sharing. This is often done indirectly, through least squares regressions testing whether idiosyncratic income shocks have a significant effect on individual consumption after controlling for the average consumption of all agents. Obstfeld (1994), Canova and Ravn (1996), and Lewis (1996) are some leading examples of this literature applied to cross-country aggregate data.

\footnotetext{
${ }^{1}$ Market completeness represents a sufficient, but not necessary, condition for perfect risk sharing. The same outcome might be achieved by, say, agreement between governments to a suitable system of transfers.

${ }^{2}$ The reason is that financial integration may also open the door to the propagation of financial turbulence from abroad. Devereux and Yu (2016) find that financial integration reduces the severity of crises as a result of better diversification, but makes them more frequent due to increased opportunities for contagion. As a consequence, the overall degree of risk may rise or fall relative to a situation of financial autarky.
} 
These conventional tests can be informative about whether perfect risk sharing holds empirically. But if the null hypothesis is rejected - as is almost invariably the case - in general they cannot say much about the extent of imperfect risk sharing present in the data. Put differently, in most cases one cannot draw inferences about the degree of risk sharing just from the magnitude of consumption correlations or estimated regression coefficients. To do this in a rigorous and meaningful way, one needs a model describing more precisely how the risk-sharing arrangement is implemented.

One leading example is the model of partial risk sharing developed by Crucini (1999). It assumes that, prior to any income realization, agents contribute a common fraction of their incomes to an income pool in exchange for the right to the same common fraction of the pooled income after shocks are realized. Thus, the fraction of their income that agents contribute to the pool has the natural interpretation of a coefficient of partial risk sharing. After income shocks are realized and transfers made according to the risk-sharing agreement, agents act as permanent-income consumers borrowing and lending at a fixed interest rate. This framework has been used by Crucini (1999), Crucini and Hess (2000), Asdrubali and Kim (2008), and Artis and Hoffmann (2008) to obtain estimates of the extent of partial risk sharing. This setting, however, suffers from a major limitation, in that all participants in the risk-sharing arrangement are assumed to contribute the same fraction of their income to the common pool. This makes the framework unsuitable for a situation in which different agents may engage in different extents of risk sharing.

This paper adds to the literature by developing an expanded version of the model in Crucini (1999) with two key features. First, each agent/country may contribute a different fraction of their income to the income pool. Second, after income shocks are realized, the transfer that each agent receives is proportional to the magnitude of her contribution to the income pool. This framework is implemented empirically to examine the extent to which different countries diversify their idiosyncratic risks, and to relate their respective degree of risk sharing to selected structural and policy characteristics. 
While the two basic features of the expanded model may seem intuitive, they have some important consequences. On the one hand, they complicate the solution of the model and its empirical implementation. Specifically, Crucini's model leads to an estimating equation in which the growth rate of an agent's consumption depends linearly on the innovation to that agent's permanent income and on the growth rate of average consumption across agents. Moreover, the parameters multiplying these variables are linear functions of the common contribution to the income pool, which makes the model suitable for OLS estimation. In contrast, the empirical implementation of the model with heterogeneous contributions to the pool requires estimating a system of equations in which the path of consumption of each agent depends on the expected evolution of the future income of all agents. Moreover, the coefficients multiplying these variables depend in nonlinear fashion on the contributions to the income pool of all agents participating in the risk-sharing agreement.

On the other hand, an additional advantage of the expanded model is that it solves a problem that plagues conventional risk-sharing regressions which include average consumption among the explanatory variables. As noted by Deaton (1990), pooling the observations on consumption of all agents in a linear regression that includes the crosssectional average of the dependent variable among the regressors leads, mechanically, to a regression coefficient of unity on that variable. Crucini (1999) dealt with this problem by estimating different coefficients of partial risk sharing for each agent (regions or countries in his analysis), even though the model is built on the assumption of a common coefficient for everyone. To obtain a single estimate, as implied by the model, Crucini then takes the average of the estimated risk-sharing coefficients of all agents. In contrast, our model does not suffer from this problem because our estimating equation is stated only in terms of the (quasi-)innovations to the present value of income growth of all agents. Unlike conventional risk-sharing regressions, it does not include the cross-sectional average of the 
dependent variable among the regressors. ${ }^{3}$

Our framework also improves upon those employed by earlier literature regarding the decision problem that agents solve after the cross-country transfers are made. While the traditional literature assumes that agents act as permanent-income consumers with quadratic preferences, we assume that agents maximize a utility function of the constant relative risk aversion form allowing for country-specific coefficients of risk aversion, discount rates, and interest rates. This generalization of the problem allows us to weaken some of the implicit assumptions used by the earlier literature. Namely, that all agents have identical preferences and face the same constant gross interest rate which, in turn, equals the reciprocal of their (common) discount factor. Borrowing from Hansen and Singleton (1983), Campbell and Mankiw (1989), and Campbell (1993), we derive a log-linear estimating equation by using a first order Taylor approximation of the intertemporal budget constraint of the representative household.

We estimate the model using a time-series cross-section dataset comprising 50 industrialized and developing countries over the period 1970-2010. We find an average coefficient of partial risk sharing of around 0.5. In terms of the model, this means that the average country contributes half its income to the income pool. The estimates, however, vary systematically between industrial and developing countries, with the former exhibiting, on average, higher degrees of risk sharing than the latter (centered around 0.59 and 0.43 , respectively). Re-estimating the model over rolling time samples, we find evidence that the degree of risk sharing has been on the rise for the average country during most of the sample period. When we split the sample between industrial and developing countries, however, we find a widening gap between industrial and developing countries: while the degree of risk sharing increased over time for industrial countries, average risk sharing for developing countries remained flat or even declined somewhat during the globalization

\footnotetext{
${ }^{3}$ Moreover, even if we had written the estimating equation in terms of a weighted consumption average, the nonlinearity of the model would break the linear relation between right and left-hand side variables inherent to the linear regression.
} 
period (although there is an uptick at the end of the sample). This result is consistent with the view that the benefits from financial globalization do not accrue evenly to all countries, and may prove elusive for many developing economies. ${ }^{4}$

In the paper's framework, these partial risk-sharing coefficient estimates can be interpreted as measuring agents' chosen contributions to the global income pool. The model, however, is silent on the factors behind those choices. To gain further insight, we assume that they reflect cross-country variation in policies, institutions, and other characteristics that help or hinder consumption risk sharing. Specifically, we re-estimate the model expressing the partial risk-sharing coefficients as a function of selected indicators of countries' structural and policy characteristics. These include financial and trade openness, which are commonly viewed as reflecting the mechanisms through which risk sharing may be actually implemented, as well as a measure of the degree of flexibility of the exchange rate, which plays a central role in the mitigation of shocks. We also include a measure of country size as determinant of the coefficient of risk sharing, because larger countries should expect smaller benefits from participating in the risk pooling agreement. In particular, for a given contribution to the income pool, the larger is the country the more correlated will be its output with the pooled income.

While this adds further complication to an already-challenging nonlinear estimation problem, it yields fairly robust empirical results. The main conclusion is that international financial integration is a significant factor behind the observed cross-country patterns of consumption risk sharing. The degree of financial integration, as summarized by a measure of de jure capital account openness, and/or by a de facto measure of total foreign asset and liability positions, is positively correlated with the coefficient of partial risk sharing, consistent with the view that financial integration improves international risk sharing. After controlling for financial integration, however, trade openness appears to affect negatively risk sharing. While we do not pursue this idea further, one potential

\footnotetext{
${ }^{4}$ On the costs and benefits of financial globalization, see Kose et al. (2009).
} 
explanation is that the impact of global terms of trade shocks on income volatility is amplified in more open economies, which - for a given degree of financial integration weakens consumption risk sharing. In addition, the degree of flexibility of the exchange rate regime also matters: floating regimes are associated with increased risk sharing, while fixed and intermediate regimes are not, which suggests that floating regimes help shelter consumption from random shocks - possibly through the ability of independent monetary policy to stabilize output and thereby consumption. Finally, the size of the economy, as measured by total population, is robustly negatively associated with the degree of risk sharing, consistent with the observation that larger countries are likely to reap smaller benefits from participating in the risk-sharing agreement.

Our paper is related to a substantial empirical literature assessing international consumption risk sharing. Sørensen et al. (2007) relate trends in risk sharing among OECD countries to their foreign assets and liabilities. They find that the degree of consumption risk sharing appears to be positively related to foreign asset holdings, while the relation with foreign liabilities is not robust. Kose, Prasad and Terrones (2009) argue that risk sharing has risen among industrial countries (but not among developing countries), and the rise is correlated with the increase in gross foreign assets and liabilities over the globalization period. Holinski, Kool and Muysken (2012) also examine how international consumption risk sharing relates to various features of countries' equity portfolios. These papers base their conclusions on conventional risk-sharing regressions, and thus they are subject to the criticism that, strictly speaking, such regressions do not provide a solid basis for inferences about the extent of partial risk sharing. Fratzscher and Imbs (2009) develop a model with transaction costs and discuss their effects on conventional tests of risk sharing. They find that larger holdings of foreign capital (especially in the form of equity or bonds) are associated with higher consumption risk sharing. In contrast, larger holdings of FDI or bank loans are not. Flood, Marion and Matsumoto (2012) use the variance of a country's share of world consumption as a measure of consumption risk sharing. Perfect 
consumption risk sharing occurs when this share is constant. Using rolling windows, they argue that consumption risk sharing rose during the recent era of financial globalization, particularly when the focus is on low-frequency movements in consumption. ${ }^{5}$

The paper closest to ours is Ho and Ho (2015) which, in independent work, developed a model with heterogeneous contributions to the income pool. There are, however, major differences between their framework and conclusions and ours. First, we are interested in comparing the differential risk sharing in the group of industrial countries relative to that in developing countries. Ho and Ho focus only on rich countries. Second, Ho and Ho use a risk-sharing rule that implies that the size of the countries participating in the agreement is irrelevant. Instead, our risk-sharing rule implies that, everything else equal, larger countries receive more from the pool because they contribute more to begin with. And third, while Ho and Ho estimate the model imposing that output growth is iid across countries and over time, we allow for more flexible income processes with temporal dependence within countries as well as cross-sectional dependence through common factors that may affect income growth of all countries simultaneously. This specification for the income process is supported by the data, and it matters for the paper's results. We discuss other differences in the body of the paper.

The rest of the paper is organized as follows. Section 2 develops the model of partial risk sharing. Section 3 describes the data and the details of the empirical implementation of the model. Section 4 discusses the main empirical results of the paper and section 5 concludes. The appendix contains some proofs and additional tables.

\footnotetext{
${ }^{5}$ Bai and Zhang (2012) develop a model with incomplete financial markets and enforceability constraints and show that removing capital controls leads to the emergence of default risk that limits risk sharing. Finally, Bengui, Mendoza and Quadrini (2013) analyze whether the international globalization of financial markets is associated with more risk sharing using a calibrated two-country model with different frictions.
} 


\section{A model of partial risk sharing}

In this section, we develop a model of partial risk sharing that generalizes the model in Crucini (1999). ${ }^{6}$ Time is discrete and there are $\mathrm{N}$ different countries. Country $i=1,2, \ldots, \mathrm{N}$ is composed of $H_{i}$ identical consumers each of whom owns a tree which yields $Y_{i, t}$ fruits at time $t$. Thus, aggregate income in country $i$ is $H_{i} Y_{i, t}$.

Consumers enter into a partial risk-sharing agreement at the beginning of time 0 , before income is realized. The agreement requires that all agents contribute a fraction of their income, possibly different across countries, into an income pool in exchange for a claim to a fraction of the aggregate pooled income. If consumers of country $i$ contribute a fraction $\lambda_{i}$ of their income to the pool, the contribution of country $i$ to the fund at time $t$ is $\lambda_{i} H_{i} Y_{i, t}$ and the aggregate pooled income equals $\sum_{j=1}^{N} \lambda_{j} H_{j} Y_{j, t} .7$

The agreement specifies that consumers in country $i$ get back a fraction

$$
\theta_{i}=\frac{\lambda_{i} \omega_{i}}{\sum_{j=1}^{N} \lambda_{j} \omega_{j}}
$$

of the income pool, where $\omega_{i}$ is a measure of the worldwide income share of country i. ${ }^{8}$ Given the fractions $\lambda_{j}$, equation (1) implies that wealthier countries get back a higher fraction of the income pool. ${ }^{9}$ Therefore, the aggregate income of country $i$ after the

\footnotetext{
${ }^{6}$ Most of the algebra required to derive the results in this section is contained in Hansen and Singleton (1983), Campbell and Mankiw (1989), and Campbell (1993). See Hevia and Servén (2018) for details.

${ }^{7}$ In this model, a perfect risk-sharing agreement would be a situation in which $\lambda_{i}=1$ for all $i=1,2, \ldots, N$. Hence the values of the $\lambda_{i}$ parameters reflect, in a reduced form, all the underlying factors that help or hinder risk sharing. Modeling how those values are chosen is beyond the scope of the paper. In section 4.4, however, we try to relate the $\lambda_{i}$ coefficients to observed variables commonly viewed as reflecting mechanisms through which risk sharing may be actually implemented in practice.

${ }^{8}$ Below we consider different definitions of $\omega_{i}$ in terms of the average income share over a pre-sample or in-sample period of varying length. All choices yield virtually identical results.

${ }^{9} \mathrm{Ho}$ and Ho (2015) use the sharing rule $\theta_{i}=\lambda_{i} / \sum_{j=1}^{N} \lambda_{j}$, which implicitly assumes that aggregate income is the same across countries. It seems natural to assume that, to contribute a given fraction of their income to the pool, wealthier agents will demand a higher fraction of the pooled income than poorer agents. Unless we use a sharing rule like (1), poorer countries will tend to receive net transfers from wealthier countries for reasons that have nothing to do with the uncertainty of their income process.
} 
risk-sharing agreement is

$$
H_{i} \bar{Y}_{i, t}=\left(1-\lambda_{i}\right) H_{i} Y_{i, t}+\theta_{i} \sum_{j=1}^{N} \lambda_{j} H_{j} Y_{j, t} .
$$

In per capita terms, each consumer of country $i$ receives

$$
\bar{Y}_{i, t}=\left(1-\lambda_{i}\right) Y_{i, t}+\lambda_{i} \sum_{j=1}^{N} \frac{\omega_{i} / H_{i}}{\omega_{j} / H_{j}} \theta_{j} Y_{j, t} .
$$

Suppose now that, on top of the risk-sharing agreement, consumers in country $i$ can invest their wealth in an asset with a gross real return $R_{i, t+1}$. Following Campbell and Mankiw (1989), we assume that the income flows after the risk-sharing agreement are capitalized into tradable wealth $W_{i, t}$. Thus, the flow budget constraint is

$$
W_{i, t+1}=R_{i, t+1}\left(W_{i, t}-C_{i, t}\right) .
$$

The preferences of consumers in country $i$ are represented by the utility function

$$
E_{t}\left[\sum_{h=0}^{\infty} e^{-\delta_{i} h} \frac{C_{i, t+h}^{1-1 / \gamma_{i}}}{1-1 / \gamma_{i}}\right],
$$

where $\gamma_{i}$ is the reciprocal of the coefficient of relative risk aversion, $\delta_{i}$ is the subjective discount rate, and $E_{t}$ is the expectation operator conditional on information at time $t$.

The Euler equation associated with the problem of maximizing (4) subject to (3) is

$$
C_{i, t}^{-1 / \gamma_{i}}=E_{t}\left[e^{-\delta_{i}} R_{i, t+1} C_{i, t+1}^{-1 / \gamma_{i}}\right]
$$

Let $c_{i, t}=\log C_{i, t}, r_{i, t+1}=\log R_{i, t+1}$, and $\Delta c_{i, t+1}=c_{i, t+1}-c_{i, t}$. Then the Euler equation can be rewritten as

$$
E_{t}\left[\exp \left(\frac{1}{\gamma_{i}}\left[\Delta c_{i, t+1}-\gamma_{i}\left(r_{i, t+1}-\delta_{i}\right)\right]\right)\right]=1
$$


Following Hansen and Singleton (1983), if consumption and returns are conditionally homoskedastic and log-normal, it follows that $\Delta c_{i, t+1}-\gamma_{i}\left(r_{i, t+1}-\delta_{i}\right)$ is normally distributed with a constant variance and a (time-varying) conditional mean $E_{t} \Delta c_{i, t+1}-\gamma_{i}\left(E_{t} r_{i, t+1}-\delta_{i}\right)$. Hence, the Euler equation becomes

$$
E_{t} \Delta c_{i, t+1}=\gamma_{i} E_{t} r_{i, t+1}-\gamma_{i} \delta_{i}+\frac{1}{2 \gamma_{i}} \operatorname{Var}\left(\Delta c_{i, t+1}-\gamma_{i} r_{i, t+1}\right)
$$

The same equation can be derived as a second-order Taylor approximation if returns and consumption growth are jointly conditionally homoskedastic (Campbell, 1993). ${ }^{10}$

With these results, we can rewrite the Euler equation as

$$
\mathrm{E}_{\mathrm{t}} \Delta \mathrm{c}_{\mathrm{i}, \mathrm{t}+1}=\zeta_{\mathrm{i}}+\gamma_{\mathrm{i}} \mathrm{E}_{\mathrm{t}} \mathrm{r}_{\mathrm{i}, \mathrm{t}+1}
$$

where $\zeta_{i}=\frac{1}{2 \gamma_{i}} \operatorname{Var}\left(\Delta c_{i, t+1}-\gamma_{i} r_{i, t+1}\right)-\gamma_{i} \delta_{i}$.

As in Campbell (1993), a log-linear approximation to the flow budget constraint (3) around the average consumption-wealth ratio $\bar{C}_{i} / \bar{W}_{i}$ yields

$$
\Delta w_{i, t+1}=r_{i, t+1}+\left(1-\rho_{i}^{-1}\right)\left(c_{i, t}-w_{i, t}\right)+k_{i}
$$

where $w_{i, t}=\log W_{i, t}, k_{i}=\log \left(\rho_{i}\right)-\left(1-\rho_{i}^{-1}\right) \log \left(1-\rho_{i}\right)$, and $\rho_{i}=1-\bar{C}_{i} / \bar{W}_{i}$. Next, using the identity $\Delta w_{i, t+1}=\Delta c_{i, t+1}+\left(c_{i, t}-w_{i, t}\right)-\left(c_{i, t+1}-w_{i, t+1}\right)$ into the previous equation we obtain a first order difference equation for $\left(c_{i, t}-w_{i, t}\right)$. Solving this difference equation

\footnotetext{
${ }^{10}$ Commault (2017) argues that traditional approximation methods either ignore the precautionary savings motive in the Euler equation, represented by the term $\operatorname{Var}_{t}\left(\Delta c_{i, t+1}-\gamma_{i} r_{i, t+1}\right)$, or assume that it is time invariant. This omission, in turn, could lead to a downward bias in the estimate of the response of consumption growth to transitory income shocks. As noted by Campbell (1993), however, the conditional log-normality of consumption and the constant conditional variance are an implication of the assumption that returns and news of future returns are jointly conditionally log-normal once we log-linearize the household's budget constraint (see Hevia and Servén, 2018). We do not view the assumption of homoskedasticity (over time) as too restrictive in a context of annual time series with a relatively short sample. Our estimation approach, however, allows for heteroskedasticy in the cross-section of countries.
} 
forward, ruling out explosive solutions, and taking time-t conditional expectations gives

$$
c_{i, t}-w_{i, t}=\sum_{s=1}^{\infty} \rho_{i}^{s}\left(E_{t} r_{i, t+s}-E_{t} \Delta c_{i, t+s}\right)+\frac{\rho_{i} k_{i}}{1-\rho_{i}} .
$$

Substituting the Euler equation (5) into the previous equation one obtains

$$
c_{i, t}-w_{i, t}=\left(1-\gamma_{i}\right) \sum_{s=1}^{\infty} \rho_{i}^{s} E_{t} r_{i, t+s}+\frac{\rho_{i}\left(k_{i}-\zeta_{i}\right)}{1-\rho_{i}}
$$

To obtain the consumption function, we follow Campbell and Mankiw (1989) and rewrite $\log$-wealth $w_{i, t}$ as a function of current and future incomes after risk sharing (details are provided in Hevia and Servén (2018)). Once we do that, we obtain

$$
c_{i, t}-\bar{y}_{i, t}=\sum_{s=1}^{\infty} \rho_{i}^{s} E_{t}\left[\Delta \bar{y}_{i, t+s}\right]-\gamma_{i} \sum_{s=1}^{\infty} \rho_{i}^{s} E_{t}\left[r_{i, t+s}\right]-\frac{\rho_{i} \zeta_{i}}{1-\rho_{i}}
$$

The consumption function (7) imposes a cointegration relation between log-consumption and log-income after risk sharing. Although we could use this expression to estimate the model, in practice saving rates display considerable persistence, and appear close to being nonstationary. ${ }^{11}$ Since our model is not designed to account for persistent movements in saving rates, we follow earlier literature and estimate the model in differences. ${ }^{12}$

Differentiating expression (7) between times $t$ and $t-1$ gives

$$
\Delta c_{i, t}=\gamma_{i} r_{i, t}+\sum_{s=0}^{\infty} \rho_{i}^{s}\left(E_{t}-\rho_{i} E_{t-1}\right)\left(\Delta \bar{y}_{i, t+s}-\gamma_{i} r_{i, t+s}\right)
$$

where, for any variable $z_{t+s}$, the expression $\left(E_{t}-\rho_{i} E_{t-1}\right)\left(z_{t+s}\right)=E_{t}\left(z_{t+s}\right)-\rho_{i} E_{t-1}\left(z_{t+s}\right)$ represents the quasi-innovation in $z_{\mathrm{t}+\mathrm{s}}$ as of time $\mathrm{t}^{13}$

\footnotetext{
${ }^{11}$ Unit root tests reported by Byrne, Fazio and Fiess (2009) and Coakley, Hasan and Smith (1999) fail to reject nonstationarity of the saving rate for the majority of the countries in their respective samples.

${ }^{12}$ Estimation in differences is commonly used in the permanent-income literature and in models of partial consumption insurance. See Campbell and Mankiw (1990), Artis and Hoffmann (2008), Asdrubali and Kim (2008), and Ho and Ho (2015), among others.

${ }^{13}$ The innovation $\left(E_{t}-E_{t-1}\right) z_{t+s}$ is the new information obtained about variable $z_{t+s}$ between times $t$
} 
In equation (8), consumption growth is expressed as a function current and future income growth after risk sharing and returns. A log-linear approximation to equation (2) around $\frac{Y_{i, t}}{Y_{j, t}}=\frac{\omega_{i} / H_{i}}{\omega_{j} / H_{j}}$ implies the following relation between income growth after and before risk sharing (Hevia and Servén, 2018),

$$
\Delta \bar{y}_{i, t}=\left(1-\lambda_{i}\right) \Delta y_{i, t}+\lambda_{i} \sum_{j=1}^{N} \theta_{j} \Delta y_{j, t},
$$

If $\lambda_{i}=0$ (i.e., country $i$ does not contribute at all to the income pool) income growth after risk sharing trivially equals income growth before risk sharing. In contrast, if $\lambda_{i}=1$ (country $i$ contributes all its income to the pool) income growth after risk sharing equals a weighted average of the income growth before risk sharing across countries, where the weights are given by the relative contribution of each country to the income pool.

Replacing equation (9) into (8) delivers an expression relating consumption growth in country $i$ with the quasi-innovation to the discounted value of income growth of all countries and the quasi-innovation to the discounted value of returns,

$$
\begin{aligned}
\Delta c_{i, t}= & \gamma_{i} r_{i, t}-\gamma_{i}\left(E_{t}-\rho_{i} E_{t-1}\right) \sum_{s=0}^{\infty} \rho_{i}^{s} r_{i, t+s}+\left(1-\lambda_{i}\right)\left(E_{t}-\rho_{i} E_{t-1}\right) \sum_{s=0}^{\infty} \rho_{i}^{s} \Delta y_{i, t+s} \\
& +\lambda_{i}\left(E_{t}-\rho_{i} E_{t-1}\right) \sum_{s=0}^{\infty} \rho_{i}^{s} \sum_{j=1}^{N} \theta_{j} \Delta y_{j, t+s} .
\end{aligned}
$$

Unfortunately, we do not have data on returns for the 50 countries and for the period that we consider. We thus assume that the current interest rate and quasi-innovations to the present value of returns are orthogonal to the quasi-innovation to the present values of income growth. Although restrictive, this assumption is much weaker than that used in most of the literature on the permanent income model and the literature on partial risk sharing that followed the seminal paper by Crucini (1999). That literature simply assumes and $t-1$. We label $\left(E_{t}-\rho_{i} E_{t-1}\right) z_{t+s}$ the "quasi-innovation" in $z_{t+s}$ because the constant $\rho_{i}$ is typically close to but smaller than 1 . 
that interest rates are constant and equal across countries. ${ }^{14}$ In contrast, our approach allows for interest rates that are random and different across countries, although we need the orthogonality assumption mentioned above to rule out problems of endogeneity.

To estimate the model we also assume that $\rho_{i}$ is constant across countries. To calibrate $\rho$, rewrite the budget constraint (3) as

$$
\left(\frac{W_{i, t+1} / C_{i, t+1}}{W_{i, t} / C_{i, t}}\right) \frac{C_{i, t+1}}{C_{i, t}}=R_{i, t+1}\left(1-\frac{C_{i, t}}{W_{i, t}}\right)
$$

In a balanced growth path, with $W_{i, t+1} / C_{i, t+1}=W_{i, t} / C_{i, t}=W / C, R_{i, t+1}=R$, and $\mathrm{C}_{\mathrm{i}, \mathrm{t}+1} / \mathrm{C}_{\mathrm{i}, \mathrm{t}}=1+\mathrm{g}$, the previous expression becomes $1+\mathrm{g}=\mathrm{R}(1-\mathrm{C} / \mathrm{W})$. But noting that $\rho=1-\mathrm{C} / \mathrm{W}$ gives

$$
\rho=\frac{1+g}{R} .
$$

Using $g=0.023$, which is the average pooled growth rate of consumption per capita in our sample period, and an average gross return of $R=1.05$, gives $\rho \approx 0.97$. Our results, however, are robust to reasonable variations in the calibrated value of $\rho$.

It is convenient to rewrite equation (10) compactly as

$$
\Delta c_{i, t}=\mu_{i}+\left(1-\lambda_{i}\right) \epsilon_{i, t}+\lambda_{i} \sum_{j=1}^{N} \theta_{j} \epsilon_{j, t}+v_{i, t},
$$

where $\epsilon_{j, t}=\left(E_{t}-\rho E_{t-1}\right) \sum_{s=0}^{\infty} \rho^{s} \Delta y_{j, t+s}$ is the quasi-innovation to the present value of country j's income growth rate, $\mu_{i}$ is the unconditional mean of $\gamma_{i} r_{i, t}-\gamma_{i}\left(E_{t}-\rho E_{t-1}\right) \sum_{s=0}^{\infty} \rho^{s} r_{i, t+s}$, and $v_{i, t}$ is defined as

$$
\nu_{i, t}=\gamma_{i} r_{i, t}-\gamma_{i}\left(E_{t}-\rho E_{t-1}\right) \sum_{s=0}^{\infty} \rho^{s} r_{i, t+s}-\mu_{i}
$$

Our objective is to estimate the degree of risk sharing $\lambda_{i}$ for each country $i=1,2, \ldots, N$.

\footnotetext{
${ }^{14}$ See, for example, Crucini (1999), Crucini and Hess (2000), Artis and Hoffmann (2008), Asdrubali and Kim (2008), and Ho and Ho (2015).
} 
This requires estimating the quasi-innovations to the present value of country $j$ 's income growth $\epsilon_{j, t}$. Let $\hat{\epsilon}_{j, t}$ denote the estimated quasi-innovation and rewrite (11) as

$$
\Delta c_{i, t}=\mu_{i}+\left(1-\lambda_{i}\right) \hat{\epsilon}_{i, t}+\lambda_{i} \sum_{j=1}^{N} \theta_{j} \hat{e}_{j, t}+u_{i, t}
$$

where the residual $u_{i, t}$ is the sum of $v_{i, t}$ and the rational expectation's error that represents the superior information of agents relative to the econometrician,

$$
u_{i, t}=v_{i, t}+\left(1-\lambda_{i}\right) \epsilon_{i, t}+\lambda_{i} \sum_{j=1}^{N} \theta_{j} \epsilon_{j, t}-\left(\left(1-\lambda_{i}\right) \hat{e}_{i, t}+\lambda_{i} \sum_{j=1}^{N} \theta_{j} \hat{\epsilon}_{j, t}\right) .
$$

Under our assumptions, $\mathfrak{u}_{i, t}$ is orthogonal to the econometrician's information set at time $t-1 .^{15}$ This information set, however, may omit some relevant information used by the agents to forecast their future incomes. The omitted information can lead to serially correlated residuals for a given agent as well as contemporaneously correlated residuals across agents. The former could be due to a persistent variable that is used by the consumer, but unobserved by the econometrician, to perform revisions to her present value of output growth. The latter could be due to an aggregate shock observed by all agents, but unobserved by the econometrician, that affects everyone's output growth.

To sum up, the key differences between our framework and that in Crucini (1999) can be summarized as follows. In both cases, the starting point is the assumption that agents contribute a fraction of their income to an income pool and have access to an asset to smooth consumption over time after transfers are realized. In Crucini (1999), however, all agents are assumed to contribute the same fraction of their income to the pool, which forces their respective partial risk-sharing coefficients $\lambda_{i}$ to be all equal and allows a drastic

\footnotetext{
${ }^{15}$ We follow the usual procedure in the rational expectations econometric literature and assume that, when performing revisions to their anticipated output paths, agents have more information than the econometrician. The proof that $u_{i, t}$ is orthogonal to the econometrician's information set at $t-1$ uses the law of iterated expectations as in Hansen and Sargent (1980). In addition, any classical measurement error in consumption can also be included in the error term $u_{i, t}$.
} 
simplification of the model. ${ }^{16}$ However, instead of estimating a single $\lambda$ for all agents, Crucini estimates $\lambda_{i}$ separately for each agent through OLS regressions, and then computes a single coefficient $\lambda$ by averaging the individual coefficients. While this procedure might be justified in Crucini's empirical application, whose focus is on relatively homogeneous groups of regions or countries - U.S. states, Canadian provinces, and G-7 countries - it is clearly less defensible in our case because we will work with a large country sample comprising both advanced and developing countries, and hence exhibiting a greater degree of heterogeneity. Indeed, one of our objectives is precisely to assess the extent to which the coefficients of partial risk sharing vary across countries. This requires a more general framework such as (12), in which different countries may exhibit different coefficients of partial risk sharing. A second difference between our frameworks is that, by using more general preferences, we are able to weaken several assumptions used by earlier literature that relied on permanent income consumers with quadratic preferences. Namely, that all agents have identical preferences and face the same constant interest rate which, in turn, equals their (common) subjective discount rate.

The added generality of our risk-sharing agreement relative to the conventional model poses additional econometric challenges too. For each country, equation (12) involves a nonlinear function of the risk-sharing coefficients of all countries. Thus, estimating the model requires more complex econometric techniques than those found in earlier literature. This is the topic of the next section.

\section{Empirical implementation}

The core of our empirical analysis is the estimation of (12) using a cross-country time-series dataset. However, the equation involves the quasi-innovations to the present value of income growth, which are not observed. We proceed on two stages. First, we construct

\footnotetext{
${ }^{16}$ This assumption is maintained in subsequent empirical applications of Crucini's framework (with the exception Ho and Ho (2015)).
} 
the innovations based on an estimated time-series model of income growth. In the second stage, we use these innovations to estimate (12). ${ }^{17}$ In this section we first discuss the econometric issues surrounding the estimation of the parameters of the risk-sharing model, and then we turn to those related to the construction of the quasi-innovations required for such task. Finally, we briefly summarize our data sources.

\subsection{Implementing the risk-sharing model}

Estimation of (12) in a cross-country setting poses a challenging problem because each country's consumption path depends in nonlinear fashion on the risk-sharing coefficients of all countries. To make this explicit in what follows, it is useful to rewrite (12) as

$$
\Delta c_{i, t}=\mu_{i}+\left(1-\lambda_{i}\right) \hat{e}_{i, t}+\lambda_{i} \sum_{j=1}^{N} \frac{\lambda_{j} \omega_{j}}{\sum_{k=1}^{N} \lambda_{k} \omega_{k}} \hat{\epsilon}_{j, t}+u_{i, t}
$$

where $u_{i, t}$ is potentially heteroskedastic and correlated across countries and over time.

To express the model in more compact form, we introduce the following notation. Let $\Delta c_{i}=\left(\Delta c_{i, 1}, \ldots, \Delta c_{i, T}\right)^{\prime}$ and $\epsilon_{i}=\left(\epsilon_{i, 1}, \ldots, \epsilon_{i, T}\right)^{\prime}$ denote the (column) vectors of consumption growth and quasi-innovations to the present discounted value of income growth of country $i$, where $T$ denotes the number of time series observations per country; and define the $\mathrm{T} \times \mathrm{N}$ matrix $\mathbf{Z}=\left(\boldsymbol{\epsilon}_{1}, \ldots, \boldsymbol{\epsilon}_{\mathrm{N}}\right)$. In addition, let $\lambda=\left(\lambda_{1}, \ldots, \lambda_{N}\right)^{\prime}$ denote the vector of risksharing coefficients, and define the $N \times N$ diagonal matrix $\Omega$ which has along its main diagonal the average income shares $\omega_{j}$, with all off-diagonal elements equal to zero. After some manipulations, the $T$ observations of (13) corresponding to the $i$-th country can be compactly written

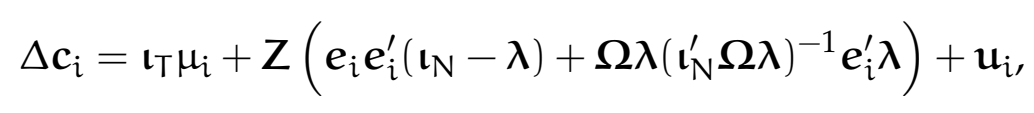

\footnotetext{
${ }^{17}$ In principle, one could combine both steps and estimate jointly the parameters of the income process and the risk-sharing model. The model, however, is heavily nonlinear and this would greatly add to the complexity of the estimation approach. For this reason, we proceed in two stages, as described in the text.
} 
where $\imath$ denotes column vector of ones and $\mathbf{e}_{i}$ is an $\mathrm{N} \times 1$ vector of zeros with a 1 in the $i$-th entry. Finally, stacking the observations on consumption growth for all countries into the NT $\times \times 1$ vector $\Delta \mathbf{c}=\left(\Delta \mathbf{c}_{1}^{\prime}, \ldots, \Delta \mathbf{c}_{N}^{\prime}\right)^{\prime}$ and letting $\boldsymbol{\mu}=\left(\mu_{1}, \ldots, \mu_{N}\right)^{\prime}$, the full system of equations can be written

$$
\Delta \mathbf{c}=\boldsymbol{\mu} \otimes \mathfrak{\iota}_{\mathrm{T}}+\left(\mathbf{I}_{\mathrm{N}} \otimes \mathbf{Z}\right)\left[\left(\boldsymbol{\lambda} \otimes \boldsymbol{\Omega} \boldsymbol{\lambda}\left(\mathfrak{l}_{N}^{\prime} \boldsymbol{\Omega} \boldsymbol{\lambda}\right)^{-1}\right)+\operatorname{vec}\left(\mathbf{I}_{\mathrm{N}}-\operatorname{diag}(\boldsymbol{\lambda})\right)\right]+\mathbf{u},
$$

where $\otimes$ denotes the Kronecker product, and $\operatorname{diag}(\lambda)$ is an $N \times N$ matrix with its main diagonal equal to $\lambda$ and zeros elsewhere.

Thus, the empirical model amounts to a system of $\mathrm{N}$ equations with cross-equation parameter restrictions. The restrictions imply that a system estimation procedure is needed, even though the explanatory variables (the quasi-innovations to the present value of income growth in all $\mathrm{N}$ countries, contained in the matrix $\mathrm{Z}$ ) are the same in all equations. In this context, we use system NLS to estimate the parameters of (15). We first partial out $\mu$ by expressing $\Delta \mathbf{c}$ and $\mathbf{Z}$ as deviations from their country-specific means; let $\Delta \tilde{\mathbf{c}}$ and $\tilde{Z}$ denote the transformed variables. Then we compute the NLS estimator that solves the problem

$$
\min _{\lambda}(\Delta \tilde{\mathbf{c}}-\boldsymbol{\phi}(\tilde{\mathbf{Z}}, \boldsymbol{\Omega}, \boldsymbol{\lambda}))^{\prime}(\Delta \tilde{\mathbf{c}}-\boldsymbol{\phi}(\tilde{\mathbf{Z}}, \boldsymbol{\Omega}, \boldsymbol{\lambda}))
$$

where $\boldsymbol{\phi}(\tilde{\mathbf{Z}}, \boldsymbol{\Omega}, \boldsymbol{\lambda})=\left(\mathbf{I}_{N} \otimes \tilde{\mathbf{Z}}\right)\left[\left(\boldsymbol{\lambda} \otimes \boldsymbol{\Omega} \boldsymbol{\lambda}\left(\mathfrak{\iota}_{N}^{\prime} \boldsymbol{\Omega} \boldsymbol{\lambda}\right)^{-1}\right)+\operatorname{vec}\left(\mathbf{I}_{N}-\operatorname{diag}(\boldsymbol{\lambda})\right)\right]$. Since the residuals may exhibit heteroskedasticity, serial correlation, cross-sectional dependence, or any combination of all three, to perform inference on $\lambda$ we use the robust covariance matrix estimator proposed by Driscoll and Kraay (1998) and Vogelsang (2012). ${ }^{18}$

This procedure yields a set of unrestricted estimates of the risk-sharing coefficients $\lambda$. However, we are also interested in learning about the covariates of risk sharing. To do this, we restrict the risk-sharing coefficients to be a function $\lambda=m(X \delta)$, where $X$ is an $N \times K_{\lambda}$

\footnotetext{
${ }^{18}$ In the formula of the covariance matrix, the usual matrix of regressors is replaced in our case by the matrix of partial derivatives $\nabla_{\lambda} f$.
} 
matrix whose $i$-th row contains the (time-invariant) covariates of risk sharing for country $i$ (including a constant). Replacing $\lambda$ in (15), estimation proceeds along the same lines as above, with the parameter vector now given by $\delta$. That is, we solve

$$
\min _{\delta}(\Delta \tilde{\mathbf{c}}-\boldsymbol{\phi}(\tilde{\mathbf{Z}}, \boldsymbol{\Omega}, \mathbf{m}(\mathbf{X} \delta)))^{\prime}(\Delta \tilde{\mathbf{c}}-\boldsymbol{\phi}(\tilde{\mathbf{Z}}, \boldsymbol{\Omega}, \mathbf{m}(\mathbf{X} \delta)))
$$

\subsection{Income prediction}

Empirical implementation of the risk-sharing model requires suitable forecasts of the future income growth. To construct them, we estimate a simple time-series model of per capita GDP growth. In order to allow for correlated shocks affecting growth in multiple countries, we use a factor approach. Specifically, we assume that per capita GDP growth can be expressed as a dynamic factor model:

$$
\Delta y_{i, t}=\alpha_{0, i}+\left(\alpha_{i, 1} \Delta y_{i, t-1}+\ldots+\alpha_{i, p} \Delta y_{i, t-p}\right)+\left(\beta_{i, 0} f_{t}+\ldots+\beta_{i, s} f_{t-s}\right)+v_{i, t},
$$

for $i=1, \ldots, N$ and $t=1, \ldots, T$. Here, $f_{t}$ is a $q \times 1$ vector of (unobserved) common factors and we assume that all parameters can vary freely across $i$. Stacking for given $t$, we have

$$
\Delta y_{\mathrm{t}}=\alpha_{0}+\boldsymbol{A}(\mathrm{L}) \Delta \mathrm{y}_{\mathrm{t}-1}+\beta(\mathrm{L}) \mathrm{f}_{\mathrm{t}}+\boldsymbol{v}_{\mathrm{t}}
$$

for $t=1, \ldots, T$, where $L$ represents the lag operator, $A(L)$ is block-diagonal, and the covariance matrix of $v_{\mathrm{t}}$ is assumed diagonal. This specification nests three cases of interest. First, if $\boldsymbol{A}(\mathrm{L})=\mathbf{0}$ and $\boldsymbol{\beta}(\mathrm{L})=\mathbf{0}$, for each $i$ per capita GDP growth is iid (as in Ho and Ho (2015)); equivalently, per capita income is a random walk with drift. Second, if $\beta(L)=0$ but $\boldsymbol{A}(\mathrm{L}) \neq \mathbf{0}$, growth follows an independent AR process in each country (Crucini, 1999). Lastly, if $\boldsymbol{A}(\mathrm{L}) \neq \mathbf{0}$ and $\boldsymbol{\beta}(\mathrm{L}) \neq \mathbf{0}$ we have a factor model, dynamic if $\mathrm{s}>0$.

To make this setting operational, assume that the unobserved factors follow the $\operatorname{AR}(\mathrm{h})$ process $\mathbf{f}_{\mathrm{t}}=\mathbf{d}(\mathrm{L}) \mathbf{f}_{\mathrm{t}-1}+\boldsymbol{\eta}_{\mathrm{t}}$. Letting $\mathrm{F}_{\mathrm{t}}=\left(\mathbf{f}_{\mathrm{t}}^{\prime}, \mathbf{f}_{\mathrm{t}-1}^{\prime}, \ldots \mathbf{f}_{\mathrm{t}-\mathrm{s}+1}^{\prime}\right)^{\prime}$, the model can be rewritten 
(ignoring $\boldsymbol{\alpha}_{0}$ for simplicity) as a static factor model:

$$
\begin{aligned}
\Delta \mathbf{y}_{\mathrm{t}} & =\mathbf{A}(\mathrm{L}) \Delta \mathbf{y}_{\mathrm{t}-1}+\mathrm{BF}_{\mathrm{t}}+\boldsymbol{v}_{\mathrm{t}}, \\
\mathrm{F}_{\mathrm{t}} & =\mathrm{D}(\mathrm{L}) \mathrm{F}_{\mathrm{t}-1}+\mathbf{G} \eta_{\mathrm{t}},
\end{aligned}
$$

or, equivalently, as a factor-augmented VAR with coefficient restrictions

$$
\left(\begin{array}{c}
\mathrm{F}_{\mathrm{t}} \\
\Delta \mathbf{y}_{\mathrm{t}}
\end{array}\right)=\left(\begin{array}{cc}
\mathrm{D}(\mathrm{L}) & \mathbf{0} \\
\mathrm{BD}(\mathrm{L}) & \mathbf{A}(\mathrm{L})
\end{array}\right)\left(\begin{array}{c}
\mathrm{F}_{\mathrm{t}-1} \\
\Delta \mathbf{y}_{\mathrm{t}-1}
\end{array}\right)+\left(\begin{array}{c}
\mathbf{G} \eta_{\mathrm{t}} \\
\mathbf{B G} \boldsymbol{\eta}_{\mathrm{t}}+\boldsymbol{v}_{\mathrm{t}}
\end{array}\right) .
$$

For the general case $\mathbf{A}(L) \neq \mathbf{0}$ and $\mathbf{B} \neq \mathbf{0}$, estimation proceeds in two steps (see Stock and Watson, 2005; Song, 2013). We first estimate $\boldsymbol{A}(\mathrm{L}), \mathbf{B}$, and $\boldsymbol{F}_{\mathrm{t}}$ doing OLS iteratively on (19). Specifically, we start with an initial guess for $F_{t}$ and update it with the first $r$ principal components of $\left(\Delta \mathbf{y}_{\mathrm{t}}-\hat{\mathbf{A}}(\mathrm{L}) \Delta \mathbf{y}_{\mathrm{t}-1}-\hat{\mathrm{B}} \hat{\mathrm{F}}_{\mathrm{t}}\right)$. We use the information criteria of Bai and $\mathrm{Ng}$ (2002) to determine the number of static factors $r$ (with $r=q(s+1)$ ). To perform inference on $\boldsymbol{A}(\mathrm{L})$ and $\mathrm{B}$, we use the results of Bai and $\operatorname{Ng}(2006,2013)$.

At the second step, we estimate $D(L)$ in (20) by OLS using the estimated $F_{t}$ from the previous step. We use standard information criteria to determine the order of $\mathbf{D}(\mathrm{L})$ (generally given by $\max (1, \mathrm{~h}-\mathrm{s})$; see Bai and $\mathrm{Ng}$, 2007).

Using these estimates, the quasi-innovations to the present value of income growth can be constructed in a straightforward manner using income growth forecasts computed recursively with (21).

\subsection{Data}

The empirical sample is dictated by data availability. We work with the fifty largest countries in the world in terms of their respective GDP (in U.S. dollars in the year 2005) for which complete annual data on consumption and income, as well as measures of de jure and de facto financial openness (as described below) could be assembled. Table A.1 in 
the appendix lists the countries included in the analysis. Taken together, they account for almost 90 percent of world GDP in the year 2005.

Data on real GDP growth, aggregate consumption growth, and total population are taken from the Penn World Tables 7.1 (PWT 7.1). Along the time dimension, our sample runs from 1970 to 2010. For our baseline estimation we use 1970-71 averages to construct the initial shares $\Omega$. The regression sample therefore runs from 1972 to 2010, and comprises 1,950 country-year observations. As explained in Section 2, for the calculation of the quasi-innovation to the discounted present value of income growth, we set $\rho=0.97$.

For our analysis of the covariates of risk sharing, we measure countries' international financial integration using data on financial openness drawn from the Chinn-Ito dataset (Chinn and Ito, 2006), updated to 2012, as well as international asset and liability positions from the Lane and Milesi-Ferretti dataset, updated up to $2011 .{ }^{19}$ In addition, we also consider trade openness (as measured by imports plus exports divided by GDP, taken from PWT 7.1) as a measure of real integration. We include a variable measuring real integration because, in the end, any redistribution of endowments due to (implicit or explicit) risk-sharing agreements should be materialized through flows of goods. Lastly, because the exchange rate regime is an important determinant of the impact of shocks on aggregate income, we add a measure of the degree of flexibility of the exchange rate, taken from Ilzetzki, Reinhart and Rogoff (2017). Specifically, we condense their 'coarse' classification into three regimes: peg, intermediate, and float. ${ }^{20}$

\section{Empirical results}

We proceed in two stages. First, we estimate the income process given by (21) and construct the quasi-innovations to the present value of income growth; then we use the latter to

\footnotetext{
${ }^{19}$ Specifically, from the former dataset we take the KAOPEN financial openness indicator, while from the latter we use the ratio of total foreign assets and liabilities to GDP.

${ }^{20}$ We take their category 1 as 'fixed', 2-3 as 'intermediate', and 4 as 'floating'.
} 
estimate the risk-sharing model (15).

\subsection{Estimation of the income process}

As already explained, we estimate three different specifications of (18).D The first one imposes $\boldsymbol{A}(L)=\mathbf{0}$ and $\boldsymbol{\beta}(L)=\mathbf{0}$ (which in turn implies that $\mathbf{B}=\mathbf{0}$ in (21)), so that each country's per capita GDP growth rate is an iid process. The second specification allows $\boldsymbol{A}(L) \neq \mathbf{0}$ but still imposes $\boldsymbol{\beta}(\mathrm{L})=\mathbf{0}$, so that each country's GDP growth is described by an AR process; experiments with both first- and second-order processes proved the former to be sufficient. ${ }^{21}$ The third specification is a factor-augmented AR model with $\mathbf{A}(\mathrm{L}) \neq \mathbf{0}$ and $\boldsymbol{\beta}(\mathrm{L}) \neq \mathbf{0}$. All three specifications allow for unrestricted cross-country heteroskedasticity and parameter heterogeneity.

Table 1 reports the estimation results and forecasting performance of the three specifications. The top half of the table summarizes the parameter estimates (except for the iid specification). With the AR(1) model, shown in the second column, the average of the country-specific autoregressive parameters equals 0.24 , and is significantly different from zero. Twenty-five of the fifty individual estimates are significantly different from zero at the 10 percent confidence level. The majority of the estimates (all but six) are positive, and all are smaller than one in absolute value (the largest one equals 0.65 ), so the estimated growth dynamics are stable. Across countries, the median adjusted R-squared of the AR(1) models exceeds 0.4. Lastly, a Wald test resoundingly rejects the null that all the AR parameters equal zero.

Next we turn to the factor-augmented AR(1) model. Most of the information criteria of Bai and Ng (2002) and Choi (2013) suggest one single static factor. This in turn implies that only the contemporaneous value of the factor enters the growth equation (18). The common factor itself exhibits little persistence; we use a first-order autoregressive process

\footnotetext{
${ }^{21}$ Standard tests could not reject the joint null that all the coefficients on twice-lagged growth equal zero, so the results are not reported here.
} 
to characterize its dynamics, but the empirical results are virtually unchanged if we instead assume the common factor to be serially uncorrelated. ${ }^{22}$

The third column of Table 1 summarizes the parameter estimates of the factor-augmented model. The average value of the country-specific autoregressive parameters increases slightly, to 0.27 . As before, all the individual estimates are smaller than one in absolute value; all but four are positive, and thirty-three of them are significantly different from zero at the 10 percent level.

We scale the global factor so that it has unit variance, and choose its sign so that the loading of the largest country (the U.S.) is positive. Across countries, the estimated loadings average 0.08 . The vast majority (all but four) are positive, and thirty five out of fifty are significantly different from zero at the 10 percent level. A Wald test shown in Table 1 confirms that the factor loadings are jointly highly significant. The global factor contributes a major fraction of the overall variance of growth - over one-fourth on average. ${ }^{23}$ The contribution is especially large among advanced countries: the 12 countries where it exceeds 50 percent comprise the U.S., Canada, and 10 European Union members. Finally, inclusion of the global factor raises substantially the explanatory power of the growth equation: across countries, the median adjusted R-squared rises to 0.56 .

As a further check on model selection, the bottom half of Table 1 reports the out-ofsample forecast performance of the three growth specifications. For this exercise, we re-estimated them setting aside the last 5 annual observations, which were then used for forecasting. According to the RMSEs in the table, the factor-augmented specification exhibits the best performance at all but the 5-year horizon, while the iid specification shows the worst.

Using the parameter estimates summarized in Table 1, the quasi-innovations to the

\footnotetext{
${ }^{22}$ The reason is that the autoregressive parameter is very small and falls short of statistical significance. However, the first-order lag improves marginally the forecasting performance of the factor model over its serially uncorrelated version, so we opt for keeping it in the model.

${ }^{23}$ The value refers to the share of the long-run variance attributable to the global factor, calculated as $\operatorname{Var}\left(\boldsymbol{\beta}_{\mathrm{i}}(\mathrm{L}) \mathbf{f}_{\mathrm{t}}\right) / \operatorname{Var}\left(1-\mathrm{L} \boldsymbol{A}_{i}(\mathrm{~L}) \Delta \mathrm{y}_{\mathrm{i}, \mathrm{t}-1}\right)$.
} 
present discounted value of income growth can be readily constructed employing (21) recursively. We construct three sets of innovations, corresponding to the three model specifications in Table 1 . The three sets of innovations are not very different from each other: their pairwise correlations exceed 0.90. In particular, the correlation between the innovations obtained from the $\mathrm{AR}(1)$ specification and those obtained from its factoraugmented version equals 0.99 , which indicates that the two sets of innovations are virtually identical. Still, as the results shown in the table give a slight advantage to the factor-augmented model, it is the primary focus of the analysis below. However, the estimates of the risk-sharing model show very little change if the AR(1) income growth specification is used instead.

\subsection{Estimation of the risk-sharing model}

Table 2 summarizes the estimates of the risk-sharing coefficients obtained using the three sets of quasi-innovations constructed in the previous step. In addition, for the purpose of comparison the table also reports the estimates obtained using the specification employed by Ho and Ho (2015), namely an iid income process and a sharing rule that has all countries sharing equally the income from the pool.

The different sets of estimates share some common features. First, although the estimation imposes no restrictions whatsoever on the parameters, the vast majority do lie between zero and one, as predicted by theory. In particular, when using our preferred specification of the income process (the factor-augmented $\mathrm{AR}(1)$ in column 4), all the country-specific parameters except one fall in the admissible zone. The remaining one is negative but not significantly so, according to a one-sided t-test. Likewise, the estimates based on the AR(1) model (column 3) yield two negative parameters, ${ }^{24}$ but again standard tests show that they are not significantly smaller than zero, neither individually nor

\footnotetext{
${ }^{24}$ The negative estimate in column 4 corresponds to Turkey, to which column 3 adds Argentina. Both countries are in the top decile of the sample in terms of consumption growth volatility.
} 
jointly. ${ }^{25}$ In contrast, the least-preferred iid specification of the income growth process (columns 1 and 2) yields a larger number of negative parameters, under both sharing rules considered: seven in column 1 (of which two significantly negative at the 10 percent level) and five in column 2 (of which one significantly negative). More broadly, assuming iid income growth leads to understated risk-sharing parameter estimates, as shown by the fact that the mean estimates in columns 1 and 2 are just about half their counterparts in columns 3 and 4 .

The other common feature is the heterogeneity of the individual-country risk-sharing parameter estimates, and in particular the fact that, for all four specifications in Table 2, the estimates are higher on average for advanced countries than for developing countries. The Wald tests at the bottom of the table confirm that these differences across estimates, as well as between the two group means, are statistically highly significant. Additional tests show that even within these two groups the individual-country coefficients display significant variation: Wald tests of equality of the risk-sharing coefficients of all the countries in each income group overwhelmingly reject the null, both for developing countries and for industrial countries.

Figure 1 plots the estimates of the individual-country risk-sharing coefficients under the four specifications (Table A.1 in the appendix reports their actual values). It can be seen that the $\mathrm{AR}(1)$ income growth process and its factor-augmented version yield very similar estimates for almost all countries - indeed, the correlation between both sets of estimates is 0.96 . In contrast, the estimates based on the iid process are fairly different from the rest - for example, their correlation with those obtained with the factor-augmented income process is just 0.71 . If the iid process is combined with the sharing rule of Ho and

\footnotetext{
${ }^{25}$ Still, given the fact that in our empirical model the risk-sharing coefficients of all countries are linked through cross-equation restrictions, one may wonder how the estimates would change if all parameters were explicitly constrained to lie within the unit interval. To investigate this issue, we re-estimated the two specifications in columns 3 and 4 of Table 2 constraining all parameters to fall within the theoreticallyadmissible region. The estimates that result are virtually indistinguishable from those shown in Table 2. In fact, the correlation between the restricted and unrestricted estimates is around 0.98 under both the AR(1) and the common-factor growth prediction models. Thus, to save space we do not report the restricted estimates.
} 
Ho (2015), the correlation is roughly the same (0.75). ${ }^{26}$

With our preferred specification, shown in column 4 of Table 2, the country-specific risk-sharing coefficients are centered around 0.50. It is worth noting that this is close to the restricted estimate (0.53) obtained when imposing equality of the risk-sharing coefficients across all countries, as in the baseline specification used by Crucini (1999).

Figure 2 shows histogram plots of the distributions of risk-sharing coefficients of the two sets of countries we consider. The advanced-country distribution lies to the right of its developing-country counterpart. The mean for industrial countries is just under 0.60 , while for developing countries it equals 0.43 . As with the overall mean, these group average estimates are not too different from those obtained by Crucini (1999) using the homogeneous model of partial risk sharing. He reports an average partial risk-sharing coefficient between 0.37 and 0.60 for the group of G7 countries over the period 1970-1987 (his estimates also vary depending on the assumed income process). In turn, Asdrubali and Kim (2008) obtain higher coefficients of partial risk sharing, namely 0.77 for a group of 15 European Union countries and 0.82 for all OECD countries, both over the period 1960-2004. Kose, Prasad and Terrones (2009), using conventional risk-sharing regressions, and Flood, Marion and Matsumoto (2012), using a different measure of imperfect risk sharing, also conclude that advanced countries exhibit higher degrees of risk sharing than developing countries.

As a robustness check, we reestimated out preferred specification using alternative time periods to compute the initial shares $\Omega$ underlying the income-sharing rule, to assess if the choice has any material effect on the risk-sharing parameter estimates. We experimented with the value of income in 1970, prior to the start of the estimation sample (1972); the average income over 1970-74 (combining pre-sample and in-sample information); and

\footnotetext{
${ }^{26}$ The two sets of estimates based on the iid process are very similar: their correlation equals 0.94 . In turn, reestimating the model using the factor-augmented income process combined with the sharing rule of Ho and Ho (2015) yields a set of estimates quite similar to those in column 4 of Table 2 - their correlation rises to 0.98 . This suggests that the different specification of the income process accounts for most of the difference between the estimates in columns 2 and 4 of Table 2.
} 
the average income over the full estimation sample. As shown in Table ??, the estimates that result in each case are virtually indistinguishable - their correlation with the baseline estimates in column 4 of Table 2 equals or exceeds 0.99 . We conclude that the choice of initial period is immaterial for our results.

\subsection{Patterns of consumption risk sharing over time}

Since the mid-1980s, the world has seen a large increase in the degree of financial integration, facilitated by the removal of barriers to international capital movements, and reflected in a steady rise in cross-border asset and liability positions (Lane and Milesi-Ferretti, 2007). This observation leads to a natural question, namely: has the rise in global integration been associated with a corresponding rise in consumption risk sharing across countries? Put differently, are countries doing a better job at sharing their idiosyncratic income shocks? To address this question, we use our model of partial risk sharing to examine the evolution of consumption risk sharing over time.

For this purpose, we calculate time-varying estimates of the parameters of the consumption risk-sharing model over rolling time samples. Specifically, we use moving windows of 20 years each. Importantly, prior to estimation of the risk-sharing model we also recalculate the innovations to the present value of income growth in the same way, by estimating the income process over matching rolling samples of 20 years of data each; this ensures that both construction of the innovations and estimation of the risk-sharing coefficients use data from the same time period. ${ }^{27}$

The results from this exercise, based on the factor-augmented specification of the income growth process, are summarized in Figure 3. The figure plots the mean of the risk-sharing parameter estimates obtained in each estimation window, along with their two standard-error bands. The top panel reports the overall mean, while the lower panels

\footnotetext{
${ }^{27}$ Similarly, for each window we recalculate the initial income shares $\Omega$ using the average of the two annual observations preceding the initial year of the window.
} 
report the means for industrial and developing countries.

The overall mean for all countries displays a rising trend, especially marked in the windows beginning around the early 1980s. From that point on, the average coefficient of risk sharing rises without interruption until the global crisis enters the estimation window. Thereafter, the average estimate shows a relatively modest decline in the last two estimation windows. Still, the mean estimates obtained in the last windows lie outside the 95-percent confidence region of the initial window, suggesting that over the entire sample period there has been a statistically significant increase in the average degree of consumption risk sharing. This is confirmed by a quick glance at the individual-country risk-sharing parameter estimates: a majority of countries (33 out of 50) exhibit higher coefficients in the final estimation window than in the initial one, and for 19 of them the increase is significant, in the sense that the final estimate lies outside the 95 percent confidence interval of the initial one.

The bottom panels of Figure 3 plot the time path of the average risk-sharing coefficients for industrial and developing countries, along with their respective two standard-error bands. There is a clear contrast between the mean estimates of the two country groups. The mean for industrial countries displays a rising trend over time, especially steep across the estimation windows that begin in the mid-1980s. The rise eventually tapers off over the last estimation windows. In contrast, there has been no discernible trend among developing countries. The figure suggests, if anything, a slight initial decline in their mean risk sharing, followed by a recovery. In fact, for the developing country mean the 95-percent confidence region of the final window is contained almost in full in that of the initial one, which suggests that no significant change has taken place. For advanced countries, however, the 95-percent confidence region corresponding to the final window lies fully outside that obtained in the initial window, pointing to a significant rise in mean risk sharing among industrial countries. Thus, this rising trend of average risk sharing among rich countries is the force behind the trend increase in overall mean risk sharing found in the top panel of 
the figure. This conclusion is confirmed by the individual country estimates: 22 of the 33 countries whose risk-sharing coefficients are higher in the final estimation window than in the initial one belong to the industrial country group, while 16 of the 17 countries whose coefficients are lower belong to the developing country group.

As already noted, the estimates in Figure 3 are based on our preferred specification of the income growth process - the factor-augmented AR(1) model. However, using instead the $A R(1)$ specification without common factors yields very similar qualitative results - i.e., advanced-country estimates display a rising trend over time (although somewhat less marked than with the factor-augmented model) while developing-country estimates remain flat. In contrast, however, the upward trend of the rich-country estimates disappears if the rolling estimation is based on the iid specification of the income growth process regardless of whether the sharing rule is the one employed in this paper or that of Ho and Ho (2015). Recall that, as shown in Table 1, the empirical performance of the iid specification is inferior to those of the other alternatives considered, both in the estimation sample as well as in out-of-sample forecasting. However, it is the specification employed by Ho and Ho (2015), who find little change in risk-sharing estimates over time. Hence, the results in this section suggest that such conclusion is not robust to the use of improved growth forecasting models.

\subsection{Covariates of consumption risk sharing}

The empirical results reported earlier unambiguously showed that the coefficients of partial risk sharing display significant heterogeneity across countries. While the country-level risk-sharing arrangement that underlies our model is admittedly an abstraction, we can interpret the variation in the estimated coefficients of partial risk sharing as reflecting crosscountry variation in policies or institutions that help or hinder consumption risk-sharing. The natural next step is to investigate if the cross-country pattern of coefficients of partial risk sharing is related to measures of financial and trade openness commonly viewed as 
reflecting the mechanisms through which risk sharing may be actually implemented. This approach has been used in previous empirical literature, which has examined the relation between summary measures of the extent and form of international financial integration, and conventional reduced-form estimates of risk-sharing coefficients. ${ }^{28}$

Formally, to explore the covariates of consumption risk sharing we re-estimate the model as specified in (17), that is, with the vector of country-specific risk-sharing coefficients given by $\lambda=m(X \delta)$, where $X$ is a matrix of time-invariant risk-sharing determinants, and $\delta$ now is the vector of parameters to be estimated..$^{29}$

Table 3 reports the estimates of $\mathcal{\delta}$ obtained using different choices of the $\mathrm{X}$ variables. All specifications include also a constant, not reported in the table. The results shown correspond to estimates obtained with quasi-innovations constructed using the factoraugmented specification of income growth (that is, the model in the last column of Table 1); results using instead AR(1)-based forecasts are very similar but are not reported to save space. For each estimate of $\delta$ we can compute the implied risk-sharing coefficients of the different countries as $\hat{\lambda}=m(X \hat{\boldsymbol{\delta}})$; these are summarized in the bottom half of the table.

The first column of Table 3 relates the degree of risk sharing to log per capita GDP. The estimate is positive and significant, in line with our earlier finding that the risk-sharing parameter estimates are larger for richer countries. The individual risk-sharing coefficients implied by this simple specification are centered around 0.55 . However, their correlation with the unrestricted estimates (shown in the first column of Table A.1) is just 0.26.

Column 2 turns to the Chinn-Ito measure of financial openness. The parameter estimate is positive and significant, implying that higher degrees of openness come along with higher consumption risk sharing. The implied country-specific risk-sharing coefficients are broadly similar to those in the previous column, and their correlation with the unrestricted estimates is similarly modest. In turn, column 3 considers a standard measure of de

\footnotetext{
${ }^{28}$ See, for example, Sørensen et al. (2007), Kose, Prasad and Terrones (2009), Fratzscher and Imbs (2009), and Holinski, Kool and Muysken (2012).

${ }^{29}$ The variables in $X$ are measured as time averages. The functional form we use is $\lambda=\exp (\mathbf{X} \delta)$, which offers the advantage of preventing negative values of $\hat{\lambda}$.
} 
facto financial integration, namely the sum of foreign assets and liabilities relative to GDP. Its role in conventional regressions of consumption risk sharing has been explored, for example, by Kose, Prasad and Terrones (2009). The estimated coefficient is positive and highly significant. Further, the correlation of the implied risk-sharing coefficients with their unrestricted counterparts rises to just under .30, although there is no discernible difference between the advanced- and emerging-country average estimates, in contrast with the preceding results. Column 4 turns to real openness, as captured by total trade over GDP. The parameter estimate is positive but insignificant. The implied risk-sharing coefficients are, on average, higher for developing countries than for industrial countries, and their correlation with the unrestricted estimates in Table 2 is less than 0.2.

Column 5 explores the role of country size. Other things equal, large countries should be expected to exhibit lower degrees of risk sharing than small ones, as their income shocks have a bigger effect on the overall income pool than do shocks to the income of smaller economies - i.e., they are, to a larger extent, common shocks - and thus they derive a smaller benefit from contributing to the income pool. To verify this conjecture, Column 2 of Table 3 relates each country's degree of risk sharing to its (log) total population. The parameter estimate is negative and highly significant. Further, the correlation of the implied risk-sharing coefficients with the unrestricted estimates rises to 0.34 .

The relative merits of alternative exchange rate regimes along various dimensions especially macroeconomic stability - have been extensively debated. Column 6 examines the relation between the degree of risk sharing and the exchange rate regime as captured by a three-way aggregation of the Ilzetzki, Reinhart and Rogoff (2017) classification. Both fixed and intermediate regimes carry negative coefficients (the floating regime is the omitted category), but they are significant neither individually nor jointly.

Column 7 reports estimation results considering simultaneously all these variables. ${ }^{30}$

\footnotetext{
${ }^{30}$ We also considered additional variables, such as countries' financial development and their degree of specialization on primary commodities. They were never significant, and to save space the results are not reported.
} 
Per capita GDP and de jure financial openness become insignificant. Further, the coefficient on the former variable is very small and negative, indicating that once the remaining variables are taken into account the level of income ceases to have an independent effect on the degree of risk sharing. In turn, the loss of significance of de jure financial openness is largely due to its correlation with the facto financial integration, which carries a positive coefficient bordering on statistical significance. As for trade openness, it now carries a negative and significant coefficient. Thus, once financial openness is taken into account, increased trade openness reduces the estimated coefficient of risk sharing. One possible explanation for this result is that, by amplifying the impact of global terms of trade shocks, increased trade openness raises the correlation between domestic income and global output, reducing the benefits from participating in the risk-sharing agreement (see e.g., Loayza and Raddatz, 2007). Likewise, both fixed and intermediate exchange regimes appear to exert a negative effect on risk sharing relative to the effect of floating regimes, likely due to the superior ability of the latter to mitigate the impact of shocks on aggregate income and thereby consumption. It is worth noting also that the risk-sharing coefficients implied by the specification in column 7 exhibit a fairly high correlation (0.44) with the unrestricted estimates in column 4 of Table 2. The range of the implied individual estimates also widens considerably relative to that found in the preceding columns of Table 3.

Finally, column 8 simplifies the specification in column 7 by imposing three parameter restrictions - namely, dropping per capita GDP and de jure financial openness from the equation, and imposing equality between the respective coefficients of the fixed and intermediate exchange rate regime dummies. A Wald test of these restrictions yields a p-value of 0.88 , thus failing to reveal any evidence against the null. The parameter estimates of the restricted equation show only small changes relative to their counterparts in the unrestricted equation, and they are all significantly different from zero (at the 10 percent level in the case of de facto financial integration). Further, the range of the implied individual-country risk-sharing parameter estimates widens further. The gap between 
their advanced- and developing-country averages, and the correlation with the unrestricted risk-sharing coefficients, all remain virtually unchanged relative to the previous column.

To conclude, these empirical exercises suggest that international integration, country size, and the exchange rate regime are significant factors behind the cross-country patterns of consumption risk sharing. Specifically, both the magnitude of countries' external portfolios and their degree of exchange rate flexibility are positively related to their performance in terms of consumption risk sharing. In contrast, the size of the economy, and its degree of real openness, show the opposite pattern.

\section{Concluding remarks}

A considerable literature is concerned with assessing the extent to which countries share their consumption risk. Much of it, however, uses empirical models designed to test the null hypothesis of perfect consumption risk sharing. Once such hypothesis is rejected - as is almost invariably the case in practice - those models do not offer a rigorous basis for inferences about the degree of imperfect risk sharing present in the data. Drawing such inferences requires an empirical model of partial risk sharing. Furthermore, unless one is willing to assume that the extent of consumption risk diversification is the same across all countries in the world, the model needs to allow for cross-country heterogeneity in the degree of risk sharing.

This paper extends the existing literature by developing an empirical model that fits those two requirements. In the model, countries contribute possibly different fractions of their income to a common pool, in exchange for a claim on the aggregate income contributed to the pool by all countries. The fraction of income contributed to the global pool by each country can be naturally interpreted as its respective degree of risk sharing. Solution of the model yields a system of equations in which each country's consumption path depends on the innovations to the present discounted value of income growth of all 
countries. Moreover, the system features nonlinear parameter restrictions across equations.

The model is implemented empirically using panel data for industrial and developing economies. Estimation results show that consumption risk sharing varies significantly across countries. On the whole, rich countries exhibit higher degrees of risk sharing than developing countries, and the gap between both country groups has widened over the period of financial globalization. Moreover, the pattern of consumption risk sharing across countries is significantly related to their degree of real and financial integration into the global economy, the flexibility of their exchange rate, and their size. Countries possessing larger stocks of international assets and/or liabilities, and more flexible exchange rate regimes, exhibit larger degrees of risk sharing. In contrast, the size of the economy and its degree of trade openness seem to hinder consumption risk sharing.

\section{References}

Artis, Michael, and Mathias Hoffmann. 2008. "Financial Globalization, International Business Cycles and Consumption Risk Sharing." Scandinavian Journal of Economics, 110(3): 447-471.

Asdrubali, Pierfederico, and Soyoung Kim. 2008. "Incomplete Intertemporal Consumption Smoothing and Incomplete Risk Sharing." Journal of Money, Credit and Banking, 40(7): 1521-1531.

Bai, Jushan, and Serena Ng. 2002. "Determining the Number of Factors in Approximate Factor Models." Econometrica, 70(1): 191-221.

Bai, Jushan, and Serena Ng. 2006. "Confidence Intervals for Diffusion Index Forecasts and Inference for Factor-Augmented Regressions." Econometrica, 74(4): 1133-1150.

Bai, Jushan, and Serena Ng. 2007. "Determining the Number of Primitive Shocks in Factor Models." Journal of Business \& Economic Statistics, 25: 52-60. 
Bai, Jushan, and Serena Ng. 2013. "Principal components estimation and identification of static factors." Journal of Econometrics, 176(1): 18-29.

Bai, Yan, and Jing Zhang. 2012. "Financial integration and international risk sharing." Journal of International Economics, 86(1): 17-32.

Bengui, Julien, Enrique G. Mendoza, and Vincenzo Quadrini. 2013. “Capital mobility and international sharing of cyclical risk." Journal of Monetary Economics, 60(1): 42-62.

Byrne, Joseph P., Giorgio Fazio, and Norbert Fiess. 2009. "The Global Side of the Investment-Saving Puzzle." Journal of Money, Credit and Banking, 41(5): 1033-1040.

Campbell, John, and N. Gregory Mankiw. 1990. “Permanent Income, Current Income, and Consumption." Journal of Business \& Economic Statistics, 8(3): 265-79.

Campbell, John Y. 1993. "Intertemporal Asset Pricing without Consumption Data." American Economic Review, 83(3): 487-512.

Campbell, John Y., and N. Gregory Mankiw. 1989. “Consumption, Income and Interest Rates: Reinterpreting the Time Series Evidence." In NBER Macroeconomics Annual 1989, Volume 4. NBER Chapters, 185-246. National Bureau of Economic Research, Inc.

Canova, Fabio, and Morten O. Ravn. 1996. "International Consumption Risk Sharing." International Economic Review, 37(3): 573-601.

Chinn, Menzie, and Hiro Ito. 2006. "What matters for financial development? Capital controls, institutions, and interactions." Journal of Development Economics, 81(1): 163-192.

Choi, In. 2013. "Model Selection for Factor Analysis: Some New Criteria and Performance Comparisons." Sogang University Working Paper 1209.

Coakley, Jerry, Farida Hasan, and Ron Smith. 1999. "Saving, Investment, and Capital Mobility in LDCs." Review of International Economics, 7(4): 632-640. 
Commault, Jeanne. 2017. "How dows consumption respond to a transitory income shock? Reconciling natural experiments and structural estimations." Ecole Polytechnique Working Paper.

Crucini, Mario J. 1999. “On International and National Dimensions of Risk Sharing." The Review of Economics and Statistics, 81(1): 73-84.

Crucini, Mario J, and Gregory D Hess. 2000. "International and Intranational Risk Sharing." In Intranational Macroeconomics. , ed. Gregory D Hess and Eric van Wincoop, Chapter 2, 37-59. NY:Cambridge University Press.

Deaton, Angus. 1990. "On risk, insurance, and intra-village consumption smoothing."

Devereux, Michael B., and Changhua Yu. 2016. “International financial integration and crisis contagion." Vancouver School of Economics Working Paper.

Driscoll, John C., and Aart C. Kraay. 1998. "Consistent Covariance Matrix Estimation With Spatially Dependent Panel Data." The Review of Economics and Statistics, 80(4): 549-560.

Flood, Robert P., Nancy P. Marion, and Akito Matsumoto. 2012. "International risk sharing during the globalization era." Canadian Journal of Economics, 45(2): 394-416.

Fratzscher, Marcel, and Jean Imbs. 2009. "Risk sharing, finance, and institutions in international portfolios." Journal of Financial Economics, 94(3): 428 - 447.

Hansen, Lars Peter, and Kenneth J. Singleton. 1983. "Stochastic Consumption, Risk Aversion, and the Temporal Behavior of Asset Returns." Journal of Political Economy, 91(2): 249265.

Hansen, Lars Peter, and Thomas J. Sargent. 1980. “Formulating and estimating dynamic linear rational expectations models." Journal of Economic Dynamics and Control, 2: 7 - 46.

Hevia, Constantino, and Luis Servén. 2018. "Supplement to "Assessing the degree of international consumption risk sharing." Universidad Torcuato Di Tella Working Paper. 
Ho, Chun-Yu, and Wai-Pin Alex Ho. 2015. “Dynamics and Heterogeneity of Inter- and Intranational Risk Sharing." Journal of Money, Credit and Banking, 47(1): 123-142.

Holinski, Nils, Clemens J.M. Kool, and Joan Muysken. 2012. “The impact of international portfolio composition on consumption risk sharing." Journal of International Money and Finance, 31(6): $1715-1728$.

Ilzetzki, Ethan, Carmen M. Reinhart, and Kenneth S. Rogoff. 2017. "Exchange Arrangements Entering the 21st Century: Which Anchor Will Hold?" National Bureau of Economic Research Working Paper 23134.

Kose, M Ayhan, Eswar Prasad, Kenneth Rogoff, and Shang-Jin Wei. 2009. "Financial Globalization: A Reappraisal." IMF Staff Papers, 56(1): 8-62.

Kose, M. Ayhan, Eswar S. Prasad, and Marco E. Terrones. 2009. “Does financial globalization promote risk sharing?" Journal of Development Economics, 89(2): 258-270.

Lane, Philip R., and Gian Maria Milesi-Ferretti. 2007. "The external wealth of nations mark II: Revised and extended estimates of foreign assets and liabilities, 1970-2004." Journal of International Economics, 73(2): 223-250.

Lewis, Karen K. 1996. "What Can Explain the Apparent Lack of International Consumption Risk Sharing?" Journal of Political Economy, 104(2): 267-297.

Loayza, Norman, and Claudio Raddatz. 2007. “The Structural Determinants of External Vulnerability." World Bank Economic Review, 21(3): 359-387.

Obstfeld, Maurice. 1994. “Are Industrial-Country Consumption Risks Globally Diversified?" In Capital mobility: the impact on consumption, investment and growth., ed. Leonardo Leiderman and Assaf Razin, Chapter 2, 13-44. Cambridge UK:Cambridge University Press. 
Obstfeld, Maurice, and Kenneth Rogoff. 2001. “The Six Major Puzzles in International Macroeconomics: Is There a Common Cause?" NBER Macroeconomics Annual, 15: 339_ 390.

Song, Minkee. 2013. "Asymptotic theory for dynamic heterogeneous panels with crosssectional dependence and its applications." Korea Institute of Finance Working Paper.

Sørensen, Bent E., Yi-Tsung Wu, Oved Yosha, and Yu Zhu. 2007. "Home bias and international risk sharing: Twin puzzles separated at birth." Journal of International Money and Finance, 26(4): 587 - 605. Financial Globalization and Integration.

Stock, James H., and Mark W. Watson. 2005. “Implications of Dynamic Factor Models for VAR Analysis." National Bureau of Economic Research, Inc NBER Working Papers.

Vogelsang, Timothy J. 2012. "Heteroskedasticity, autocorrelation, and spatial correlation robust inference in linear panel models with fixed-effects." Journal of Econometrics, 166(2): 303-319. 
Figure 1: Estimates of risk-sharing coefficients

The top left panel of the figure displays a scatter plot with the estimated coefficients of risk sharing $\lambda$ obtained assuming iid income growth (vertical axis) and those obtained using an unobserved factor model of income growth (horizontal axis). The top right panel displays a similar scatter plot but assuming that income growth follows independent AR(1) processes for each country (vertical axis) and using the factor model (horizontal axis). The bottom right panel plots the estimated coefficients of risk sharing obtained assuming that income growth is iid and using the Ho and Ho (2015) sharing rule (vertical axis) and those obtained using the unobserved factor model (horizontal axis).
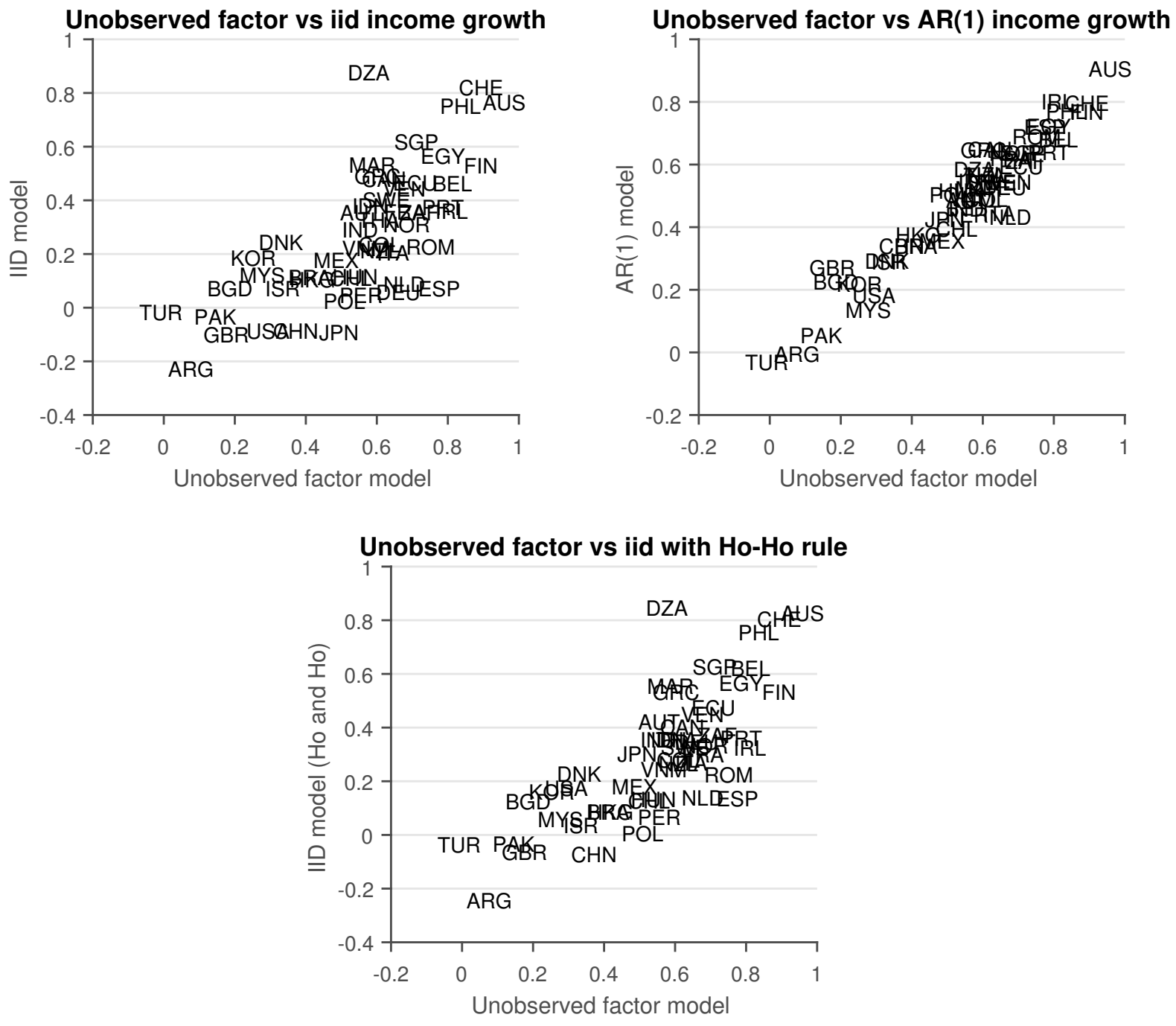
Figure 2: Histograms of estimated risk-sharing coefficients

The figure displays histograms of the estimated coefficients of partial risk sharing $\hat{\lambda}_{i}$ for the groups of advanced and developing countries, using the unobserved factor model to forecast future income growth.

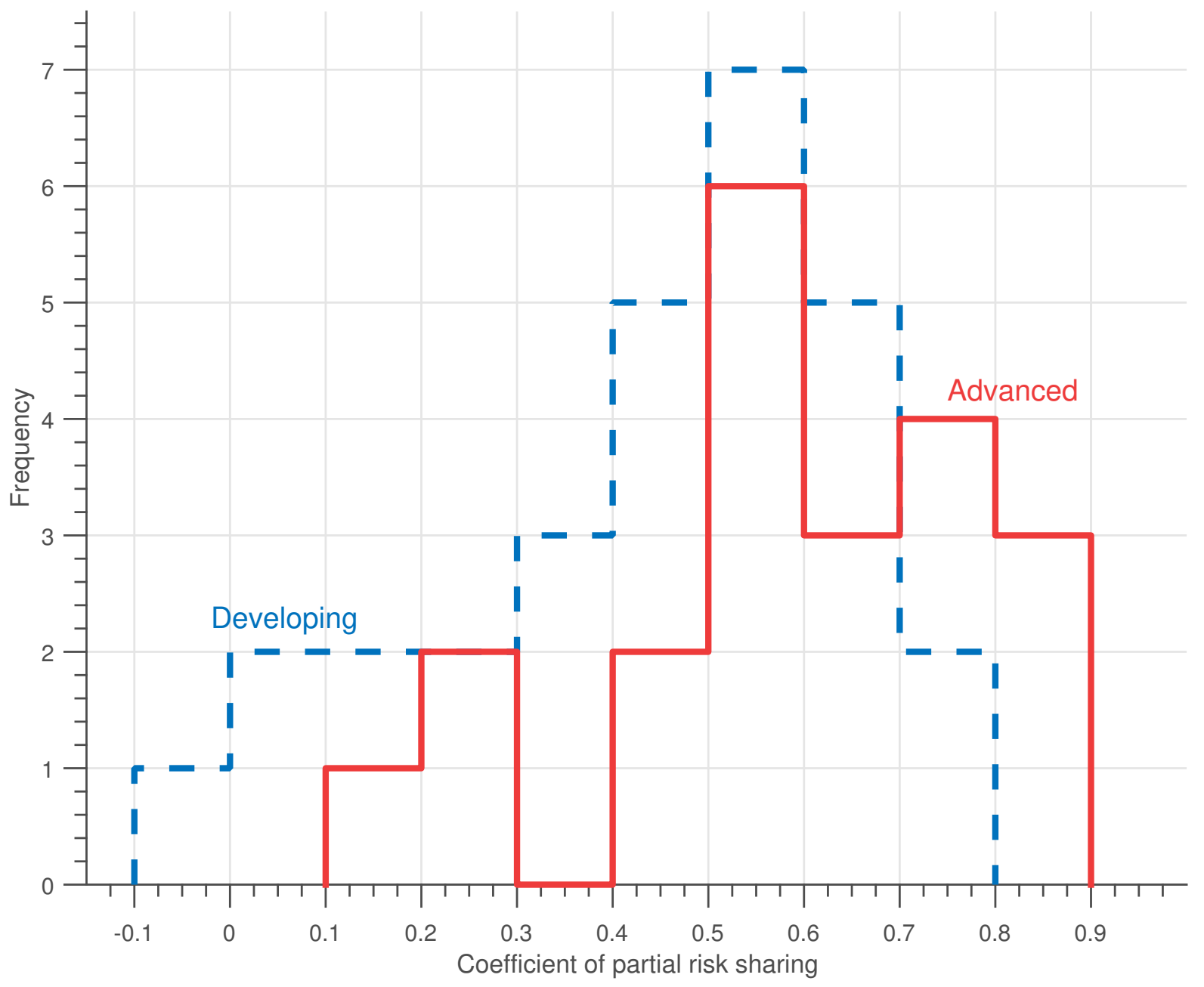


Figure 3: Evolution of estimated risk-sharing coefficients

The figure displays the average coefficient of risk sharing for all countries (top panel), advanced countries (bottom left panel), and developing countries (bottom right panel) including 90 percent confidence bands. The estimates were computed using rolling samples of 20 years each and using the unobserved factor model to forecast future income growth. The first window corresponds to the years 1972-1991; the second, the years 1973-1992; and so forth until the years 1990-2009.
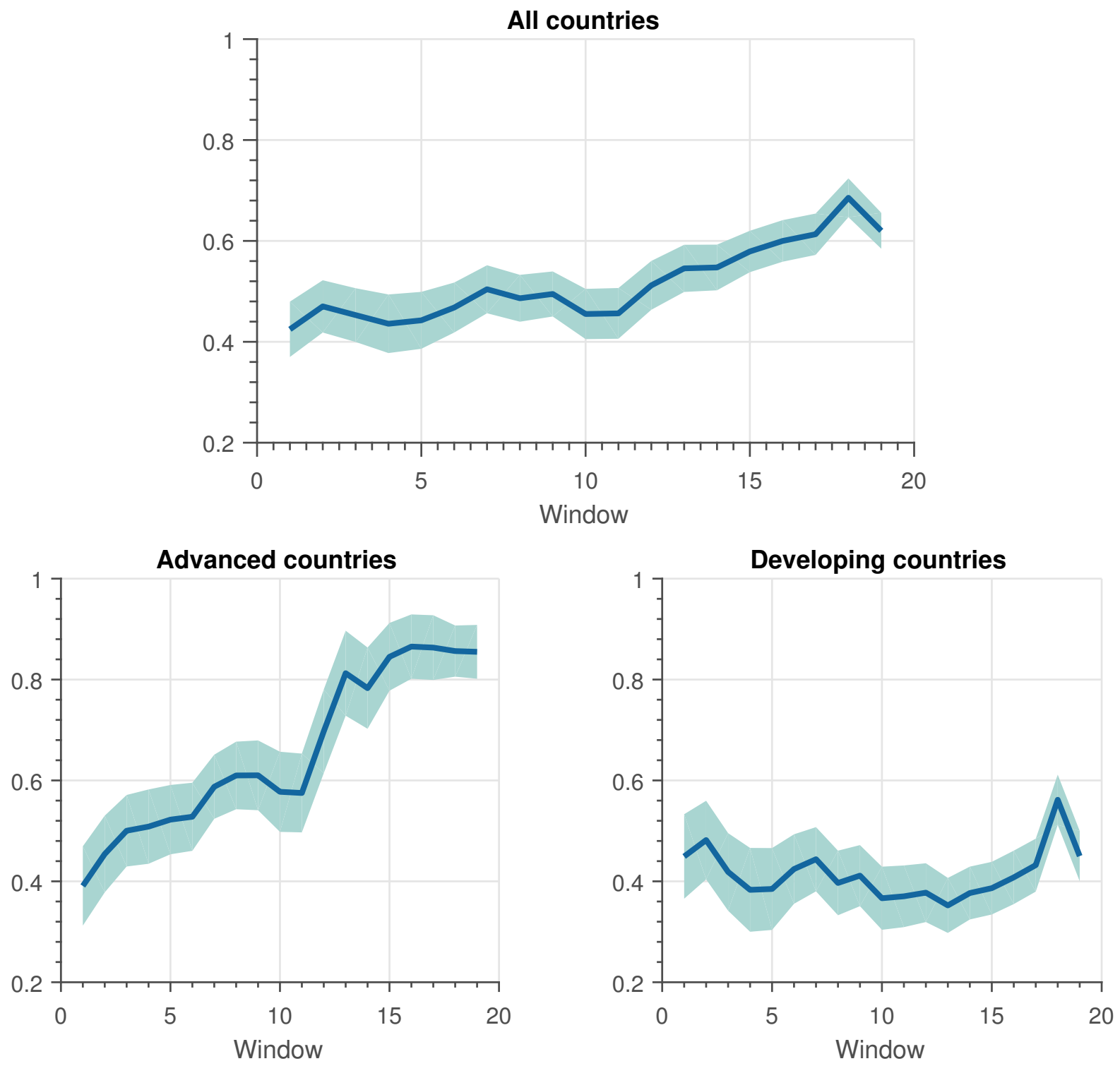
Table 1: Estimates of the income prediction model

The table reports the estimates and the forecasting performance of different models of the income process: IID assumes that each country's per-capita GDP growth is an iid process; $\mathrm{AR}(1)$ imposes a first-order autoregressive process for per-capita GDP growth independent across countries; and FAPAR(1) refers to a factor augmented model in which each country's per-capita GDP growth depends on its own lagged value and an unobserved global factor. Robust t-statistics appear in parentheses. The Wald test statistics are distributed as chisquare with 50 degrees of freedom.

\begin{tabular}{|c|c|c|c|}
\hline & IID & $\operatorname{AR}(1)$ & FAPAR(1) \\
\hline \multicolumn{4}{|l|}{ Lagged GDP growth } \\
\hline Mean of the country-specific AR estimates & - & $\begin{array}{c}0.24 \\
(11.044)\end{array}$ & $\begin{array}{c}0.27 \\
(13.656)\end{array}$ \\
\hline Number of significant (10\%) AR estimates & - & 25 & 33 \\
\hline \multicolumn{4}{|l|}{ Global factor } \\
\hline Mean of the country-specific loadings & - & - & $\begin{array}{c}0.01 \\
(17.466)\end{array}$ \\
\hline Average long-run variance contribution & - & - & 0.27 \\
\hline Number of significant $(10 \%)$ factor loadings & - & - & 35 \\
\hline Median $\overline{\mathbf{R}}^{2}$ & & 0.42 & 0.56 \\
\hline \multicolumn{4}{|l|}{ Wald test of joint significance (p-values) } \\
\hline Lagged GDP growth & - & 0.00 & 0.00 \\
\hline Global factor loadings & - & - & 0.00 \\
\hline \multicolumn{4}{|l|}{ Out of sample forecast performance (\% RMSE) } \\
\hline 1-step ahead & 2.62 & 2.26 & 2.21 \\
\hline 2-step ahead & 2.56 & 2.46 & 2.46 \\
\hline 3-step ahead & 3.09 & 3.03 & 2.99 \\
\hline 4-step ahead & 6.49 & 6.44 & 6.39 \\
\hline 5-step ahead & 3.15 & 3.15 & 3.17 \\
\hline
\end{tabular}


Table 2: NLS estimates of the country-specific risk-sharing coefficients Robust t-statistics in parentheses, using spatial-correlation consistent standard errors of Driscoll and Kraay (1998). The Wald test statistics at the bottom of the table are distributed as chi-square with 50 degrees of freedom. Column (2) refers to the IID income case using the Ho and Ho (2015) sharing rule.

\begin{tabular}{lcccc}
\hline & $(1)$ & $(2)$ & $(3)$ & $(4)$ \\
Income forecasting models & IID & IID-2 & AR(1) & FAPAR(1) \\
\hline \multicolumn{5}{l}{ Summary statistics of risk-sharing coefficient estimates } \\
Risk-sharing coefficients between 0 and 1 & 43 & 45 & 48 & 49 \\
of which significantly positive & 29 & 30 & 43 & 40 \\
Risk-sharing coefficients greater than 1 & 0 & 0 & 0 & 0 \\
$\quad$ of which significantly greater than 1 & 0 & 0 & 0 & 0 \\
Risk-sharing coefficients smaller than 0 & 7 & 5 & 2 & 1 \\
$\quad$ of which significantly smaller than 0 & 2 & 1 & 0 & 0 \\
Median & 0.22 & 0.29 & 0.52 & 0.53 \\
Maximum & 0.87 & 0.84 & 0.90 & 0.90 \\
Minimum & -0.23 & -0.24 & -0.03 & -0.07 \\
Average estimates & & & & \\
All countries & 0.26 & 0.29 & 0.49 & 0.50 \\
Advanced countries & $(13.2)$ & $(14.5)$ & $(27.7)$ & $(27.7)$ \\
Developing countries & 0.30 & 0.32 & 0.57 & 0.59 \\
& $(10.0)$ & $(11.6)$ & $(23.3)$ & $(23.9)$ \\
& 0.24 & 0.18 & 0.42 & 0.43 \\
Wald test of difference in means (p-value) & $(9.6)$ & $(9.4)$ & $(18.2)$ & $(17.2)$ \\
Wald test of joint significance of all & 0.00 & 0.00 & 0.00 & 0.00 \\
risk-sharing coefficients & 0.00 & 0.00 & 0.00 & 0.00 \\
\hline
\end{tabular}




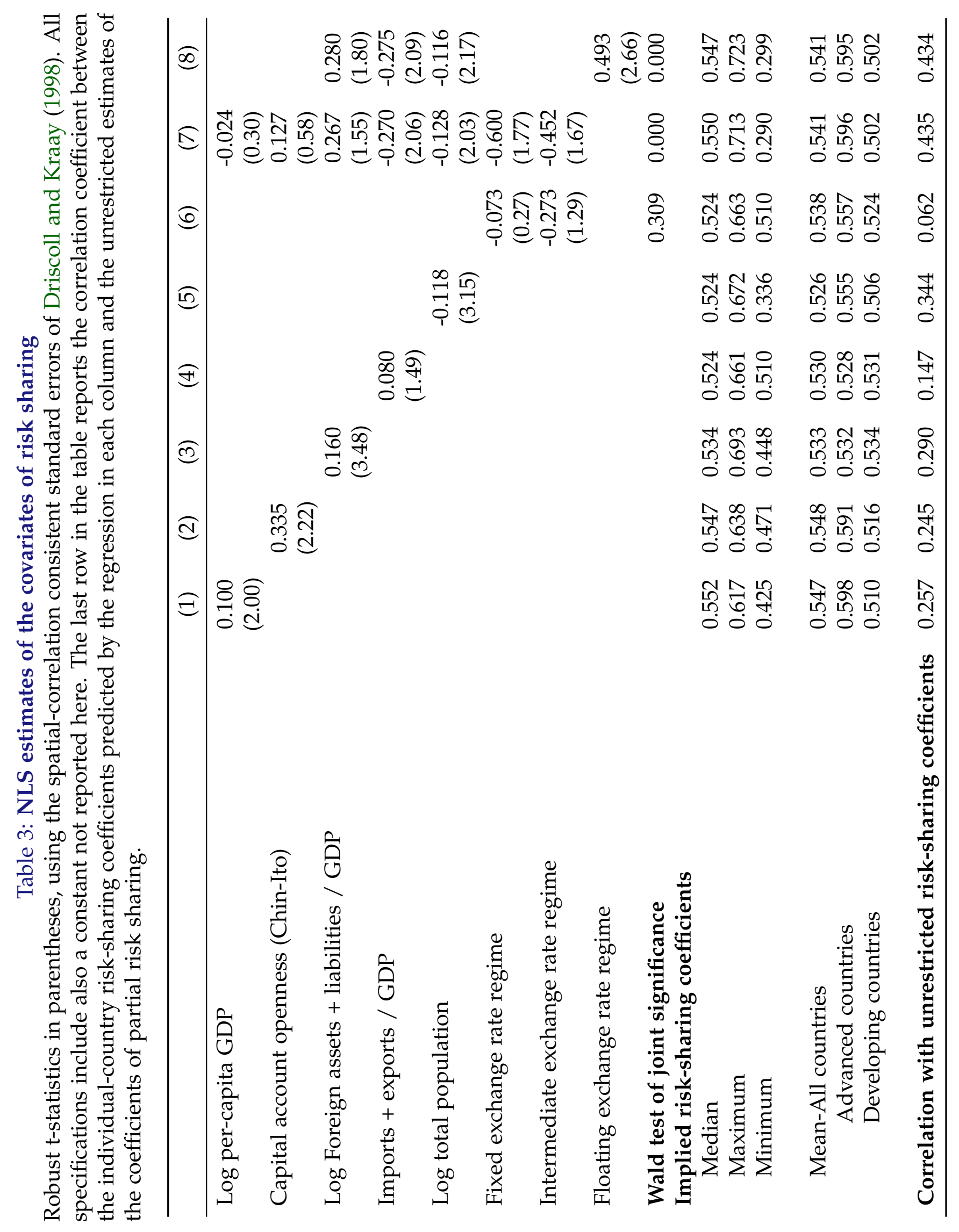


Table A.1: List of countries and estimated coefficients of partial risk sharing The table lists the group of countries used in the analysis and the country-specific estimates of the coefficients of partial risk sharing $\lambda_{i}$ for different models of the income process: IID assumes that each country's per-capita GDP growth is an iid process; AR(1) imposes a first order autoregressive process for per-capita GDP growth independent across countries; and FAPAR(1) refers to a factor augmented model in which each country's per-capita GDP growth depends on its own lagged value and a global factor. IID-2 refers to IID income growth using Ho and Ho (2015) sharing rule.

\begin{tabular}{|c|c|c|c|c|c|c|c|c|c|}
\hline \multicolumn{3}{|c|}{ Advanced countries } & \multicolumn{7}{|c|}{ Developing countries } \\
\hline & $\operatorname{FAPAR}(1)$ & $\operatorname{AR}(1)$ & IID & IID-2 & & $\operatorname{FAPAR}(1)$ & $\operatorname{AR}(1)$ & IID & IID-2 \\
\hline Australia & 0.898 & 0.904 & 0.762 & 0.824 & Algeria & 0.518 & 0.582 & 0.874 & 0.843 \\
\hline Austria & 0.496 & 0.485 & 0.352 & 0.420 & Argentina & 0.012 & -0.007 & -0.230 & -0.247 \\
\hline Belgium & 0.757 & 0.677 & 0.460 & 0.618 & Bangladesh & 0.122 & 0.224 & 0.070 & 0.120 \\
\hline Canada & 0.558 & 0.647 & 0.476 & 0.400 & Brazil & 0.351 & 0.338 & 0.111 & 0.084 \\
\hline Denmark & 0.267 & 0.291 & 0.239 & 0.226 & Chile & 0.467 & 0.392 & 0.107 & 0.124 \\
\hline Finland & 0.845 & 0.764 & 0.525 & 0.531 & China & 0.308 & 0.337 & -0.090 & -0.076 \\
\hline France & 0.620 & 0.618 & 0.354 & 0.298 & Colombia & 0.548 & 0.487 & 0.233 & 0.276 \\
\hline Germany & 0.598 & 0.526 & 0.056 & 0.343 & Ecuador & 0.645 & 0.592 & 0.463 & 0.472 \\
\hline Greece & 0.537 & 0.643 & 0.488 & 0.529 & Egypt & 0.723 & 0.719 & 0.564 & 0.563 \\
\hline Ireland & 0.765 & 0.800 & 0.358 & 0.322 & Hong Kong & 0.354 & 0.373 & 0.103 & 0.084 \\
\hline Italy & 0.600 & 0.442 & 0.201 & 0.265 & Hungary & 0.475 & 0.512 & 0.114 & 0.131 \\
\hline Japan & 0.437 & 0.422 & -0.096 & 0.299 & India & 0.502 & 0.456 & 0.287 & 0.353 \\
\hline Netherlands & 0.619 & 0.430 & 0.086 & 0.135 & Indonesia & 0.530 & 0.544 & 0.378 & 0.353 \\
\hline New Zeal. & 0.553 & 0.566 & 0.211 & 0.264 & Israel & 0.285 & 0.287 & 0.069 & 0.034 \\
\hline Norway & 0.618 & 0.635 & 0.307 & 0.329 & Korea, Rep. & 0.188 & 0.216 & 0.183 & 0.158 \\
\hline Portugal & 0.727 & 0.636 & 0.372 & 0.357 & Malaysia & 0.213 & 0.133 & 0.119 & 0.056 \\
\hline Spain & 0.716 & 0.717 & 0.069 & 0.133 & Mexico & 0.422 & 0.353 & 0.175 & 0.176 \\
\hline Sweden & 0.560 & 0.538 & 0.398 & 0.325 & Morocco & 0.522 & 0.520 & 0.529 & 0.553 \\
\hline Switzerland & 0.831 & 0.794 & 0.818 & 0.800 & Pakistan & 0.086 & 0.053 & -0.036 & -0.036 \\
\hline U.K. & 0.112 & 0.268 & -0.104 & -0.068 & Peru & 0.495 & 0.437 & 0.045 & 0.064 \\
\hline \multirow[t]{9}{*}{ U.S.A. } & 0.233 & 0.179 & -0.090 & 0.171 & Philippines & 0.778 & 0.767 & 0.749 & 0.752 \\
\hline & & & & & Poland & 0.449 & 0.501 & 0.023 & 0.001 \\
\hline & & & & & Romania & 0.682 & 0.688 & 0.224 & 0.223 \\
\hline & & & & & Singapore & 0.649 & 0.634 & 0.615 & 0.625 \\
\hline & & & & & South Africa & 0.663 & 0.608 & 0.353 & 0.369 \\
\hline & & & & & Thailand & 0.546 & 0.564 & 0.323 & 0.352 \\
\hline & & & & & Turkey & -0.069 & -0.034 & -0.019 & -0.038 \\
\hline & & & & & Venezuela & 0.616 & 0.542 & 0.442 & 0.446 \\
\hline & & & & & Vietnam & 0.502 & 0.489 & 0.219 & 0.240 \\
\hline
\end{tabular}


Table A.2: Estimates of the country-specific risk-sharing coefficients with alternative periods for initial share calculation

The table uses the FAPAR(1) process for GDP growth. Tests of significance are based on spatial-correlation consistent standard errors of Driscoll and Kraay (1998). Column "Baseline" is the baseline specification (shown in column 4 of Table 2) using 2 years of presample data to compute initial shares. Columns "1-year" and "5-years" respectively use 1 year of presample data and 5 years of in-sample data to compute initial shares. Column "Full sample" uses the entire sample to compute initial shares.

Baseline 1-year 5-years Full sample

\section{Summary statistics}

Number of coefficients between 0 and 1 of which significantly positive

Number of coefficients greater than 1 of which significantly greater than 1

Number of coefficients smaller than 0 of which significantly smaller than 0

Median

Maximum

Minimum

$\begin{array}{cccc}49 & 49 & 49 & 49 \\ 40 & 40 & 40 & 40 \\ 0 & 0 & 0 & 0 \\ 0 & 0 & 0 & 0 \\ 1 & 1 & 1 & 1 \\ 0 & 0 & 0 & 0 \\ 0.53 & 0.53 & 0.53 & 0.53 \\ 0.90 & 0.90 & 0.90 & 0.90 \\ -0.07 & -0.07 & -0.07 & -0.06\end{array}$

Correlation with baseline estimates

$\begin{array}{llll}- & 1.00 & 1.00 & 0.99\end{array}$

